\title{
Signaling hierarchy downstream of retinoic acid that independently regulates vascular remodeling and endothelial cell proliferation
}

\author{
Brenda L. Bohnsack, ${ }^{1,3,4}$ Lihua Lai, $^{2,3,4}$ Pascal Dolle, ${ }^{5}$ and Karen K. Hirschi ${ }^{1,2,3,4,6}$ \\ Department of ${ }^{1}$ Molecular and Cellular Biology and ${ }^{2}$ Pediatrics, ${ }^{3}$ Children's Nutrition Research Center, and ${ }^{4}$ Center for Cell \\ and Gene Therapy, Baylor College of Medicine, Houston, Texas 77030, USA; ${ }^{5}$ Institut de Genetique et de Biologie \\ Moleculaire et Cellulaire, CNRS/INSERM/ULP/College de France, BP 163, 67404 Illkirch Cedex, C. U. De Strasbourg, France
}

\begin{abstract}
We previously demonstrated that during vascular morphogenesis, retinoic acid (RA) is required for the control of endothelial cell proliferation and capillary plexus remodeling. Herein, we investigate the mechanisms by which RA regulates these processes in the yolk sac. We found that although the enzyme required for RA production during early embryogenesis, retinaldehyde dehydrogenase-2 (Raldh2), was expressed in the visceral endoderm, RA receptors $\alpha 1$ and $\alpha 2$ were expressed in endothelial cells in the mesoderm, indicating that they are direct targets of RA. In Raldh2-/- embryos, there was down-regulation of TGF- $\beta 1$, fibronectin (Fn) and integrin $\alpha 5$, which was associated with decreased visceral endoderm survival and production of VEGF-A, Indian hedgehog (IHH), and bFGF. Exogenous provision of RA or Fn to Raldh2 ${ }^{-/-}$explants in whole mouse embryo culture restored vascular remodeling, visceral endoderm survival, as well as integrin $\alpha 5$ expression and its downstream signaling that controls endothelial growth. Exogenous provision of visceral endoderm-derived factors (VEGF-A, IHH, and bFGF) failed to rescue endothelial cell proliferative control but collectively promoted vascular remodeling, suggesting that these processes are independently regulated via a signaling hierarchy downstream of RA.
\end{abstract}

[Keywords: Vascular development; mouse; retinoic acid; TGF- $\beta$; fibronectin]

Received January 9, 2004; revised version accepted April 9, 2004.

Blood vessel formation in the yolk sac is essential for embryogenesis. Signals such as VEGF-A (Shalaby et al. 1995; Ferrara et al. 1996) and Indian hedgehog $\left(\mathrm{IHH}_{\text {; }}\right.$ Belaoussoff et al. 1998; Baron 2001; Dyer et al. 2001), produced by extraembryonic visceral endoderm, induce the mesoderm to form blood islands composed of angioblasts and hematopoietic progenitors. Endothelial cells within the blood islands proliferate, migrate, and coalesce to form an initial capillary network. Cell-cell and cell-matrix interactions as well as onset of blood flow result in endothelial cell maturation, vascular network remodeling, and recruitment of mural cells to form a mature circulatory system.

In murine models, targeted mutations in multiple signaling pathways in both visceral endoderm (VEGF-A [Carmeliet et al. 1996; Ferrara et al. 1996; Damert et al. 2002], IHH [Byrd et al. 2002], bFGF [Lee et al. 2000], quaking [qk; Noveroske et al. 2002]) and mesoderm

${ }^{6}$ Corresponding author.

E-MAIL khirschi@bcm.tmc.edu; FAX (713) 798-1230.

Article and publication are at http://www.genesdev.org/cgi/doi/10.1101/ gad.1184904
(TGF-ß1 [Dickson et al. 1995; Chang et al. 1999; Goumans et al. 1999; Larsson et al. 2001], fibronectin [Fn; George et al. 1993, 1997], $\alpha_{5}$ integrin [Yang et al. 1993]) have illustrated a common phenotype, the inability to remodel the initial capillary plexus, resulting in yolk sac vascular inadequacy and embryonic lethality. Thus, vascular remodeling is a complex process involving interactions between visceral endodermal, endothelial and mesenchymal cells, and extracellular matrix (ECM); however, specific roles of each pathway in the remodeling process, as well as the hierarchy among these signals, remain undetermined.

Another mutant that shares this phenotype is one that is retinoic acid (RA) deficient due to targeted mutation of the retinaldehyde dehydrogenase (Raldh) 2 gene. RA is derived from vitamin A (retinol), which circulates complexed to retinol-binding protein (RBP) and transthyretin (Ttr; Soprano and Blaner 1994). RBP receptors mediate retinol uptake into cells (Bavik et al. 1995), where it is then bound to cellular RBPs (CRBP I, II; Ong et al. 1994). Conversion of retinol into active RA is a multistep process requiring retinol dehydrogenases $(\mathrm{RoDH})$ and Raldhs (Clagett-Dame and DeLuca 2002). Before embry- 
Bohnsack et al.

onic cardiac function and blood flow, yolk sac visceral endoderm expresses RBP and CRBPI and takes up and stores maternally derived retinol (Bavik et al. 1997; Sapin et al. 1997). Furthermore, in the rat yolk sac, the visceral endoderm expresses both RoDH and Raldh enzymes, suggesting that RA is locally produced by the visceral endoderm (Bavik et al. 1997).

During early mouse development, the last step in RA synthesis is dependent on Raldh2 enzyme (Niederreither et al. 1997; Ulven et al. 2000). Lack of Raldh2 gene expression generates a RA-deficient mutant that dies by embryonic day 10.5 (E10.5) with multiple defects, including shortened anteroposterior axis, absent limb buds, dilated heart, and lack of organized extraembryonic vessels in the yolk sac (Niederreither et al. 1999).

Our previous studies demonstrated that yolk sac vascular development is disrupted in Raldh2 ${ }^{-/-}$mutants prior to cardiac function and systemic circulation. Furthermore, our studies revealed that RA is required to suppress endothelial cell cycle progression via up-regulation of $\mathrm{p} 21$ and $\mathrm{p} 27$. Abnormal proliferation, associated with suppressed endothelial cell maturation, is partially responsible for lack of capillary plexus remodeling; however, circulating RA, provided via maternal diet for progressively longer time periods (E7.5-E8.5, E7.5-E9.5, or E7.5-E12.5) first restores remodeling and secondarily restores endothelial cell cycle control (Lai et al. 2003). These results suggest that endothelial cell proliferation and plexus remodeling are independently regulated by RA.

The current studies are aimed to define the cellular and molecular mechanisms by which RA regulates endothelial cell growth and vascular remodeling. We found that RA produced in visceral endoderm directly targeted endothelial cells through RA receptors (RAR) $\alpha 1$ and $\alpha 2$. RA signaling induced TGF- $\beta$-dependent Fn deposition between the visceral endoderm and mesoderm, which appears to play two independent roles. Fn was required for suppression of endothelial cell proliferation via interactions with integrin $\alpha 5$. Decreased levels of integrin $\alpha 5$ led to enhanced signaling through endothelial cell expressed integrin $\alpha \mathrm{v}$, which increased proliferation by activating the MAPKs, ERK1/2. Furthermore Fn was required for the maintenance of extraembryonic visceral endoderm survival and production of signaling molecules VEGF-A, IHH, and bFGF, which did not effect endothelial cell growth but collectively promoted vascular remodeling. Thus, our studies delineate a hierarchy among distinct signaling pathways downstream of RA that independently control endothelial cell growth and remodeling, as well as define reciprocal interactions between visceral endoderm and mesoderm required for vascular morphogenesis.

\section{Results}

$R A$ synthesis and signaling in the yolk sac

Localization of the Raldh2 gene transcripts in the extraembryonic region during vasculogenesis has not been well defined. Semiquantitative (sq) RT-PCR analysis of RNA isolated from E5.5 embryos and extraembryonic region of early streak embryos (E6.5) indicated that Raldh2 was not expressed at these stages (Fig. 1A).

A

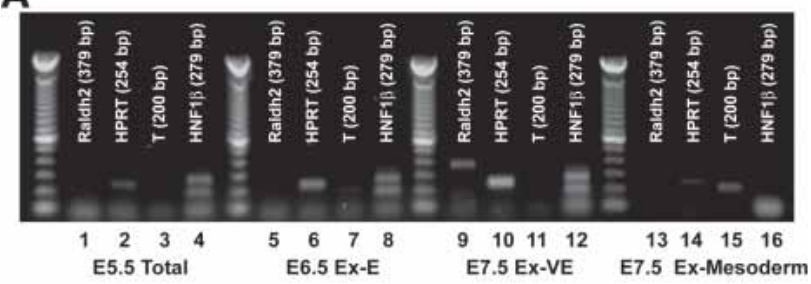

B

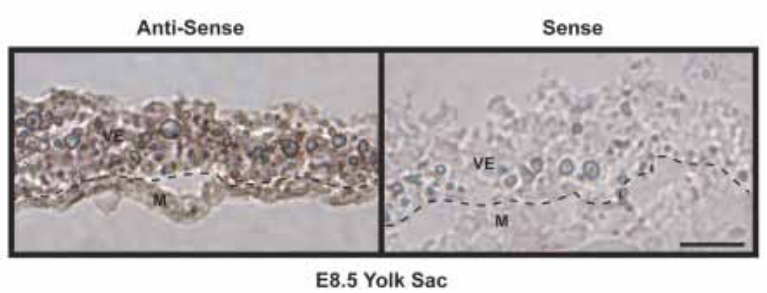

C

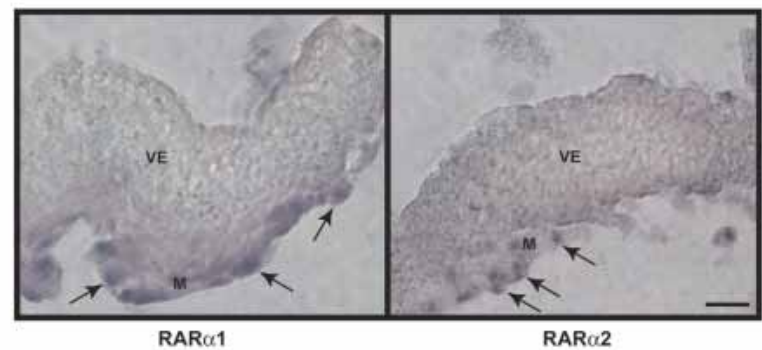

D

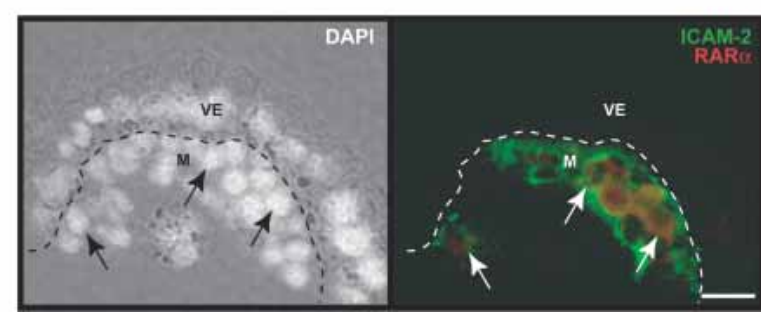

Figure 1. RA synthesis and signaling in the yolk sac. $(A)$ Raldh2 gene expression was not detected by sqRT-PCR in RNA isolated from total E5.5 embryos (lanes 1-4) and the extraembryonic region of E6.5 embryos (lanes 5-8). RNA was also independently isolated from E7.5 visceral endoderm (lanes 9-12) and mesoderm (lanes 13-16). Raldh2 transcript was most prevalent in visceral endoderm at E7.5. HNF1 $\beta$ and T-brachyury $(\mathrm{T})$ served as markers for visceral endoderm and mesoderm, respectively, and HPRT was used as an internal control. (B) In situ hybridization demonstrated that in E8.5 embryos, Raldh2 was most highly expressed in visceral endoderm, but is also in some endothelial cells. Bar, $25 \mu \mathrm{m}$. (C) In situ hybridization localized RAR $\alpha 1$ and $\alpha 2$ transcripts within the mesoderm (arrows) of E8.5 yolk sac. Bar, $25 \mu \mathrm{m}$. (D) Immunofluorescence was used to colocalize RAR $\alpha$ proteins with ICAM-2, a marker for endothelial cells (arrows) in E8.5 yolk sac. Bar, $25 \mu \mathrm{m}$. (M) Mesoderm; (V) visceral endoderm. 
In the extraembryonic region of early-to-late allantoic bud stage embryos (E7.5), the exocoelomic cavity is surrounded by an inner mesoderm layer and an outer visceral endoderm layer. To further localize Raldh2 expression, visceral endoderm and mesoderm of E7.5 extraembryonic regions were separated, and RNA was isolated from each germ layer. sqRT-PCR analysis using HPRT as an internal control demonstrated that Raldh2 was predominantly expressed in visceral endoderm (Fig. 1A). HNF1 $\beta$ and T, markers of extraembryonic visceral endoderm and mesoderm, respectively, were included to confirm clean dissection of the layers. At the five- to sevensomite stage (E8.5), in situ hybridization confirmed that Raldh2 was mainly expressed in visceral endoderm (Fig. 1B). These results are consistent with those found in the developing rat (Bavik et al. 1997) and indicate that RA is locally produced in the yolk sac starting at E7.5.

We previously demonstrated by using specific receptor agonists that the effects of RA on endothelial cell growth are mediated by RAR and not Retinoid X receptors (Lai et al. 2003). Thus, to analyze the targets of RA in the yolk sac, we determined the expression patterns of distinct RAR isoforms. Previous studies have established that transcripts for $\operatorname{RAR} \alpha$, but not $\operatorname{RAR} \beta$ and $\operatorname{RAR} \gamma$, are expressed in E8.5 yolk sac (Sapin et al. 1997). These studies did not discriminate between specific isoforms of RAR $\alpha$ or determine their localization. We demonstrated via RT-PCR that RAR $\alpha 1$ and RAR $\alpha 2$-but not RAR $\alpha 3$, RAR $\alpha 4, \operatorname{RAR} \alpha 5, \operatorname{RAR} \alpha 6$, or RAR $\alpha 7$-were expressed in E8.5 yolk sac (data not shown). In situ hybridization demonstrated that RAR $\alpha 1$ and $\operatorname{RAR} \alpha 2$ transcripts were localized to the mesoderm of E8.5 yolk sac (Fig. 1C, arrows). Furthermore, RAR $\alpha$ protein was colocalized with a marker for endothelial cells, ICAM-2, by immunofluorescence (Fig. 1D). These results indicate that RA produced in visceral endoderm targets endothelial cells within the mesoderm.

\section{Downstream targets of $R A$ in the endothelium}

To determine downstream targets of RA in endothelial cells, Raldh2 $2^{-/-}$yolk sacs were analyzed for known regulators of vascular development. TGF- $\beta 1$ is expressed in blood islands starting at E7.5 (Akhurst et al. 1990), and mutant mice lacking components of the TGF- $\beta 1$ signaling pathway have a similar vascular phenotype to the Raldh2 ${ }^{-/-}$mice (Dickson et al. 1995; Chang et al. 1999; Oh et al. 2000; Larsson et al. 2001). sqRT-PCR and Western blot analyses indicated that in E8.5 Raldh2 ${ }^{-/-}$yolk sacs, TGF- $\beta 1$ transcript and protein levels were decreased to $50 \%$ of wild-type levels (Figs. 2A,C, 3G, black bars). Immunohistochemistry revealed that TGF- $\beta 1$ protein, expressed in endothelial cells of E8.5 wild-type yolk sacs (Fig. 2D, top row, white arrows), was decreased in Raldh $2^{-/-}$yolk sacs. A primary role of TGF- $\beta 1$ in yolk sac vascular development is proposed to be the regulation of Fn synthesis by the mesoderm /Goumans et al. 1999). In E8.5 Raldh2 ${ }^{-/-}$yolk sacs, Fn production was decreased compared with that in wild type, as indicated by sqRT-PCR (Figs. 2A, 3G, black bars), in situ hybrid- ization (Fig. 2B, top row, arrows), and Western blot analyses (Fig. 2C). Furthermore, Fn protein deposition between the mesoderm and visceral endoderm layers was decreased in E8.5 Raldh2 ${ }^{-/}$mutants (Fig. 2D, middle row, black arrows). In contrast, Collagen I (Col I) transcript levels (Fig. 2A,B, bottom row, arrows) and protein deposition (Fig. 2D, bottom row) in Raldh2 ${ }^{-/-}$mutants were similar to that of wild type, indicating no global effects of RA on ECM production but rather a selective effect on Fn production.

\section{$R A$ regulation of $F n$ is mediated by TGF- $\beta 1$}

TGF- $\beta 1$ regulation of Fn production has been described in vitro in numerous cell types, including bovine pulmonary artery endothelial cells (Ignotz and Massague 1986; Ignotz et al. 1987; Shanker et al. 1999). To investigate whether TGF- $\beta 1$ mediates RA regulation of Fn, we cultured bovine aortic endothelial cells in the presence of $1 \mu \mathrm{M}$ RA or $1 \mathrm{ng} / \mathrm{mL}$ TGF- $\beta 1$ for up to $72 \mathrm{~h}$; Fn protein levels were determined by Western blot analysis. At $48 \mathrm{~h}$, untreated cells showed a slight increase in Fn production; however, RA increased Fn protein expression over control levels (Fig. 2E,G). TGF- $\beta 1$ dramatically upregulated $\mathrm{Fn}$ in a time-dependent manner beginning at $12 \mathrm{~h}$ (Fig. 2F). To determine whether TGF- $\beta 1$ mediated RA-induced Fn production, we treated endothelial cells for $48 \mathrm{~h}$ with RA or TGF- $\beta 1$ in the presence or absence of $10 \mu \mathrm{g} / \mathrm{mL}$ neutralizing antisera against TGF- $\beta 1$, TGF- $\beta 2$, and TGF- $\beta 3$. As expected, both RA and TGF- $\beta 1$ increased Fn protein levels (Fig. 2G); however, treatment with RA in the presence of neutralizing anti-TGF- $\beta$ suppressed Fn up-regulation. These results indicate that in endothelial cells, RA regulation of Fn is mediated via TGF- $\beta 1$ signaling.

\section{$R A$ regulation of visceral endoderm survival and function}

ECM deposition between the mesoderm and visceral endoderm is proposed to promote visceral endoderm survival (Goumans et al. 1999); however, this has not been demonstrated in vivo. Thus, we measured the effects of RA-deficiency-induced down-regulation of Fn on visceral endoderm survival and function. TUNEL analysis on E8.5 Raldh2 ${ }^{-1-}$ yolk sacs revealed a 15 -fold increase in apoptotic cells, which were clustered together in the extraembryonic visceral endoderm (Fig. 3A, top row, arrows). There was no difference in levels of apoptosis in

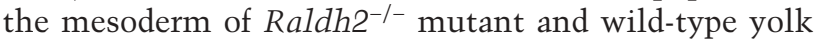
sacs, as previously reported (Lai et al. 2003). The increased apoptosis in extraembryonic visceral endoderm occurred between E7.5 and E8.5, as TUNEL analysis of E7.5 Raldh2 ${ }^{-/-}$and wild-type yolk sacs revealed no difference in apoptosis in the visceral endoderm or mesoderm (data not shown).

Increased cell death of extraembryonic visceral endoderm suggests that production of proteins such as VEGF- 
Bohnsack et al.

Figure 2. RA regulation of TGF- $\beta 1$ and $F n$ in endothelial cells. $(A)$ sqRT-PCR revealed decreased expression of TGF- $\beta 1$ and Fn transcripts in E8.5 Raldh2 ${ }^{-/-}$yolk sacs compared with wild type (WT). Col I transcript levels were similar in both Raldh2-/- and wild-type yolk sacs; HPRT was used as an internal control. (B) In situ hybridization of E8.5 yolk sac sections revealed that Fn (top) and Col I (bottom) transcripts were expressed in the mesoderm (arrows); however, Fn transcript levels

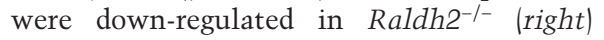
compared with wild type (WT; left). Bar, 25 $\mu \mathrm{m}$. (C) Western blot analyses of E8.5 Raldh2 ${ }^{-/-}$mutant and wild-type (WT) yolk sacs demonstrated decreased levels of TGF- $\beta 1$ and $\mathrm{Fn}$ protein. Actin was used as a loading control. $(D)$ Immunohistochemistry of E8.5 yolk sac sections revealed that levels of TGF$\beta 1$ protein (top row), specifically expressed in endothelial cells (arrows), and Fn protein (middle row), deposited between the visceral endoderm and mesoderm (black arrows), were decreased in Raldh2 ${ }^{-1-}$ yolk sac (right) compared with wild type (WT; left). Protein levels of Col I (bottom row) were similar in Raldh2 $2^{-/-}$and wild type. Bar, $25 \mu \mathrm{m}$. $(E-G)$ Bovine aortic endothelial cells were cultured for up to $72 \mathrm{~h}$ in the presence of $1 \mu \mathrm{M}$ RA $(D)$ or $1 \mathrm{ng} / \mathrm{mL}$ TGF- $\beta 1(F)$. Western blot demonstrated that RA increased Fn production over control levels at $24 \mathrm{~h}(E, G)$. TGF- $\beta 1$ significantly increased $\mathrm{Fn}$ production in endothelial cells starting at $12 \mathrm{~h}(F, G)$. $(G)$ Neutralizing anti-sera against TGF- $\beta 1$, TGF- $\beta 2$, and TGF$\beta 3$ suppressed RA-induced Fn production in endothelial cells, as well as TGF- $\beta 1$-induced Fn production. (M) Mesoderm; (V) visceral endoderm.
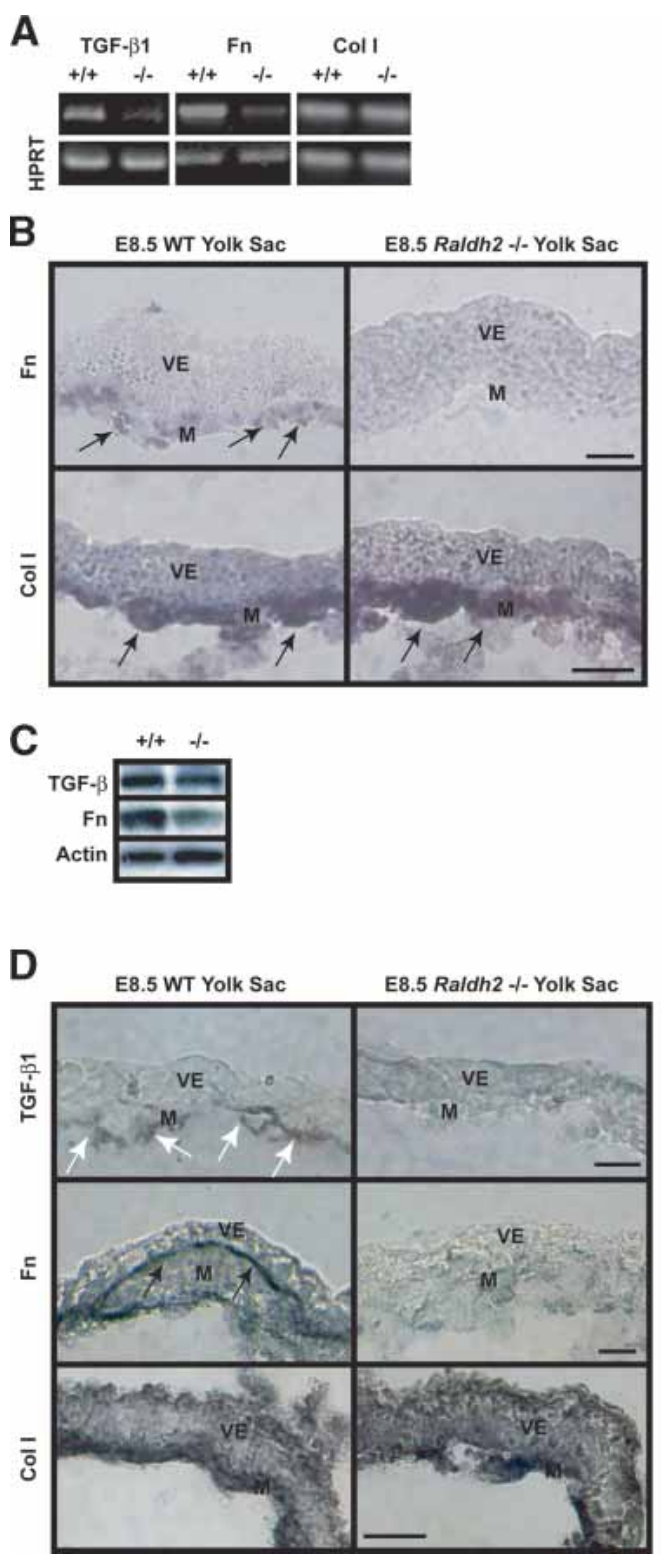

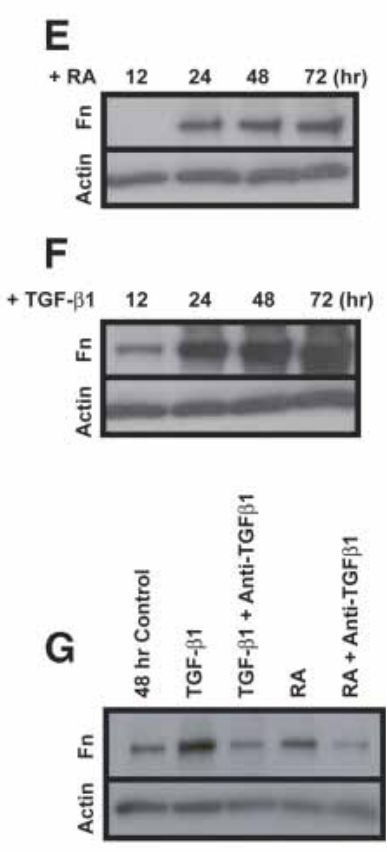

A, IHH, bFGF, and qk, known to be necessary for vascular development, could be altered in RA-deficient mutants. sqRT-PCR of E8.5 Raldh2-/- yolk sacs compared with wild type indicated that VEGF-A, IHH, bFGF, and qk transcripts were down-regulated (Fig. 3B,G, black bars). In situ hybridization for qk (Fig. 3C, top row) and immunohistochemistry and Western blot analyses for VEGF-A protein (Fig. 3D,E) confirmed the down-regulation of these factors in extraembryonic visceral endoderm in E8.5 Raldh2 ${ }^{-/-}$mutants. In addition to its role in vascular development, the visceral endoderm forms an epithelial barrier between maternal trophoblast sinuses and the embryo. Claudin 7 (Cldn7), a RA-regulated tightjunction protein (Kubota et al. 2001) that may facilitate barrier function, was also down-regulated in extraembryonic visceral endoderm of E8.5 Raldh2 ${ }^{-/-}$yolk sacs (Fig. 3B,C, middle row). These results indicate an overall im- pairment of extraembryonic visceral endoderm in protein production and barrier function in response to disrupted Fn production in yolk sac mesoderm.

In addition to increased apoptosis of the visceral endoderm, decreased production of these signals could be due to defective visceral endoderm differentiation from primitive endoderm. sqRT-PCR of visceral endoderm markers, Gata-4, Gata-6, and Ttr, however, demonstrated no differences between E8.5 Raldh2 $^{-{ }^{-}}$and wildtype yolk sacs (data not shown). Furthermore, sqRTPCR (Fig. 3B) and in situ hybridization (Fig. 3C, bottom row) analysis of the embryonic visceral endoderm marker, AFP, revealed no differences between E8.5 Raldh2 ${ }^{-/-}$and wild type, indicating that the visceral endoderm defects in E8.5 Raldh2 ${ }^{-/-}$mutants result from loss of integrity and survival not impaired differentiation. 
A
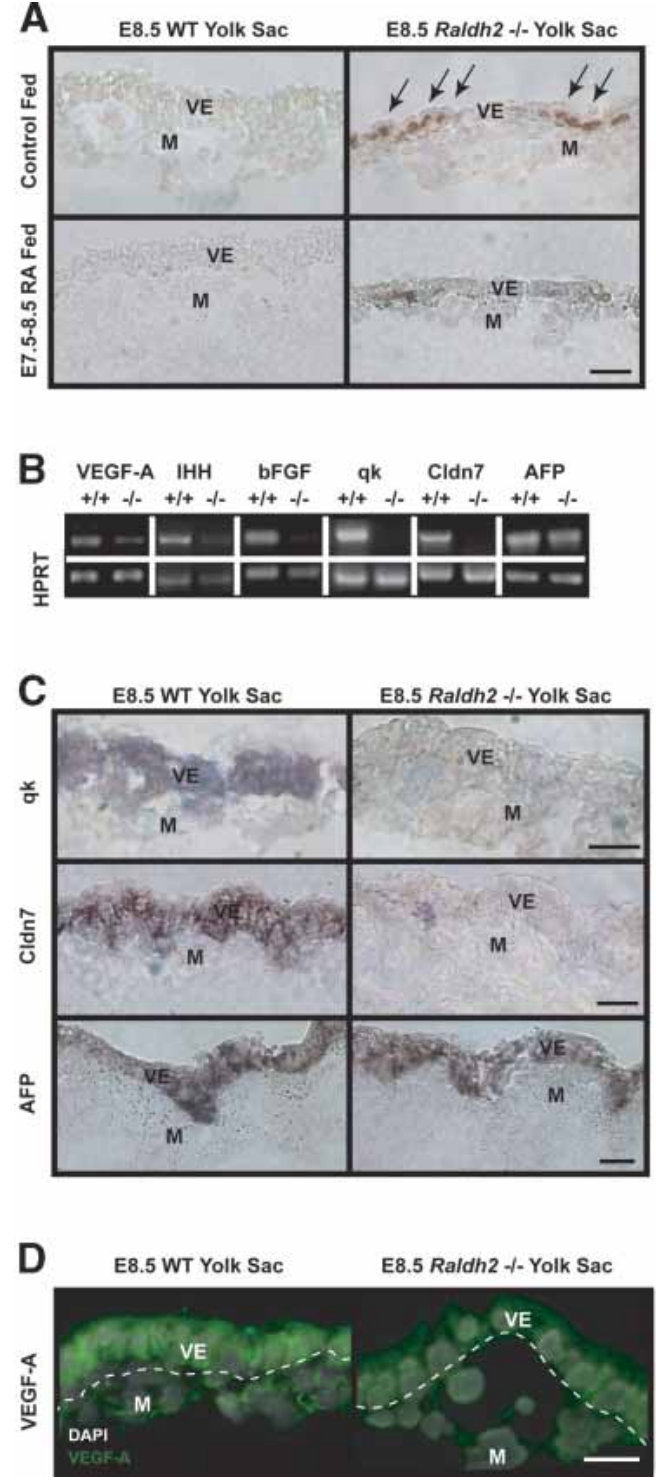
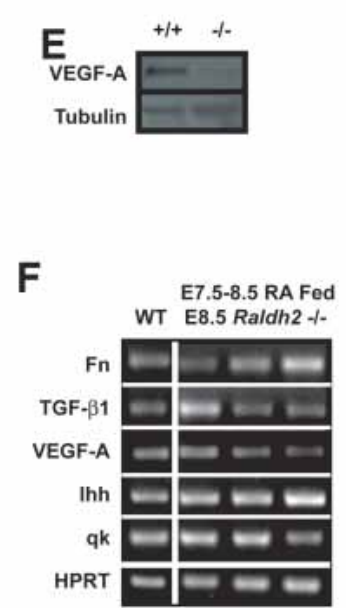

G

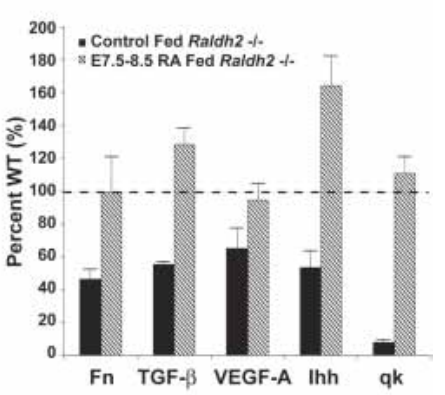

Figure 3. RA maintains visceral endoderm integrity and differentiated function. (A) TUNEL assay revealed a 15 -fold increase of apoptotic cells localized to extraembryonic visceral endoderm in control (top) E8.5 Raldh2 ${ }^{-/-}$yolk sacs (right) compared with wild type (WT; left). Feeding RA to pregnant mothers from E7.5-E8.5 decreased visceral endoderm apoptosis by 11-fold in E8.5 Raldh2 ${ }^{-/-}$yolk sacs (bottom). Bar, 25 m. (B) sqRT-PCR demonstrated that in E8.5 yolk sacs, levels of VEGF-A $_{164}, \mathrm{IHH}, \mathrm{bFGF}, \mathrm{qk}$, and Claudin 7 (Cldn7) were down-regulated in Raldh2-/versus wild type (WT); AFP was similar in Raldh2 $2^{-/-}$and wild type. HPRT was used as an internal control. $(C)$ In situ hybridization of E8.5 yolk sac sections for qk (top row), and Cldn7 (middle row) localized these transcripts to extraembryonic visceral endoderm where they were downregulated in Raldh2 ${ }^{-1-}$ (middle). (Bottom row) AFP transcripts were localized to the embryonic visceral endoderm and were similar in Raldh2 $2^{-/-}$and wild type. Bar, 25 $\mu \mathrm{m}$. $(D, E)$ Immunofluorescence and Western blot analyses for VEGF-A protein revealed decreased levels in E8.5 Raldh2 ${ }^{-1}$ mutant yolk sacs compared with wild type (WT). Tubulin was used as a loading control. (F) Feeding pregnant mothers RA from E7.5-E8.5 restored transcript levels of TGF- $\beta 1, F n$, VEGF- $\mathrm{A}_{164}, \mathrm{IHH}$, and qk in three individual E8.5 Raldh2 ${ }^{-/-}$yolk sacs to wild-type (WT) levels as determined by sqRT-PCR. $(G)$ sqRT-PCR of RNA from control (black bars) and RA fed (striped bars) E8.5 Raldh2 ${ }^{-/-}$yolk sacs, represented as percent of similarly fed wild-type littermates, demonstrated that RA restored levels of transcripts down-regulated in control-treated Raldh2 ${ }^{-/-}$yolk sacs. $n=4-5$. (M) Mesoderm; (V) visceral endoderm.

\section{$R A$ rescues $\mathrm{Raldh}^{-/-}$vascular defects in vivo}

Previous studies have shown feeding pregnant mothers subteratogenic doses of RA from E7.5-E8.5 restores vascular remodeling and enables Raldh2 $2^{-/-}$mutants to survive until E12.5 (Lai et al. 2003). We performed further RA feeding studies and demonstrated that E7.5-E8.5 was the critical time period, as feeding pregnant females RA from E6.5-E7.5 or E8.5-E9.5 failed to rescue the Raldh2 $2^{-/-}$mutants (data not shown). This time frame correlates with the expression of Raldh2 enzyme and RA production.

Feeding RA to pregnant mothers from E7.5-E8.5 partially restored extraembryonic visceral endoderm sur-

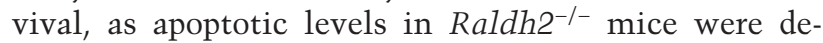

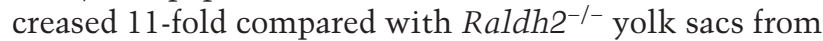
control-fed litters (Fig. 3A, bottom row). In addition, feeding RA from E7.5-E8.5 restored transcript levels of TGF- $\beta 1$, Fn, qk, VEGF-A, and IHH in individual Raldh2 $2^{-/-}$yolk sacs (Fig. 3F,G, striped bars). Thus, it is possible that RA rescue of TGF- $\beta 1$-mediated Fn production in the mesoderm restores visceral endoderm integrity and function during vascular development.

\section{$R A$ rescues Raldh2 ${ }^{-/-}$vascular defects in vitro}

To further analyze the roles of downstream targets of RA and determine their hierarchy in the control of vascular remodeling and endothelial cell proliferation, we performed in vitro rescues of Raldh2 ${ }^{-/-}$mutants in whole mouse embryo culture. Early-to-late allantoic bud Raldh2 $2^{--}$and wild-type embryos (E7.5) were placed in control conditions for $48 \mathrm{~h}$, after which vascular morphology was assessed. Yolk sacs of wild-type embryos exhibited expected large branching vessels and remodeled capillaries networks, as highlighted by dashed lines (Fig. 4A, left column). Blood rhythmically pumped by the embryonic heart was evident throughout the wild-type yolk sac vasculature. Yolk sac vascular development was 
Bohnsack et al.

Figure 4. In vitro Raldh2-/- yolk sac vascular phenotype and rescue with RA. (A) Wild-type (WT; left) and Raldh2-/- (right) explants after 48 $\mathrm{h}$ in control conditions in whole embryo culture

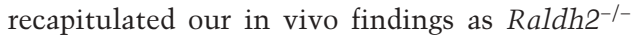
yolk sac failed to remodel (top row; bar, $100 \mu \mathrm{m}$ ). Dashed lines highlight vascular patterning in yolk sac. Whole-mount immunostaining of yolk sac tissues (second row; bar, $100 \mu \mathrm{m}$ ) with antiphosphohistone-3 demonstrated a twofold increase in the mitotic index of endothelial cells in Raldh2 ${ }^{-/}$explants compared with wild type $(\mathrm{WT})$, also corroborating in vivo findings. Furthermore, immunofluorescence (third row; bar, $25 \mu \mathrm{m})$ to colocalize phosphohistone-3 (green) with VE-Cad (red) demonstrated that the proliferating cells were predominantly endothelium (arrows). TUNEL assay of yolk sac sections (fourth row; bar, $25 \mu \mathrm{m}$ ) revealed a 10-fold increase in apoptosis in extraembryonic visceral endoderm (VE, white arrows) of Raldh2-/- explants. The level of apoptosis in mesoderm $(\mathrm{M}$,

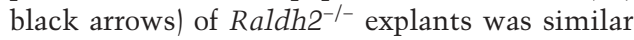
to that of wild type. Detection of Fn protein by immunofluorescence (bottom row; bar, $25 \mu \mathrm{m}$ ) demonstrated decreased Fn deposition specifically between the visceral endoderm and meso-

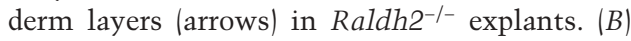
Addition of $3 \mathrm{ng} / \mathrm{mL}$ RA to culture media restored vascular remodeling in yolk sacs of Raldh2-/- explants (top) and had no effect on wild-type development. Whole-mount (middle row; bar, $100 \mu \mathrm{m}$ ) immunostaining with antiphosphohistone-3 and immunofluorescence (bottom row; bar $25 \mu \mathrm{m}$ ) with antiphosphohistone-3 (green) and VE-cad (red) revealed that RA restored endothelial cell cycle control in Raldh2-/- explants to wild-type level.

slightly delayed compared with in vivo development, and after $48 \mathrm{~h}$, the development of E7.5 explants was similar to E9.0 embryos in vivo. Yolk sacs of Raldh2 ${ }^{-/-}$ embryos after 48-h culture were similar to E9.0 Raldh2 ${ }^{-/-}$in vivo as they had formed an initial capillary plexus (Fig. 4A, right column) but exhibited no remodeling, as emphasized by dashed lines.

Consistent with our previous in vivo studies, phosphohistone-3 staining revealed a 1.9-fold increase in the mi-

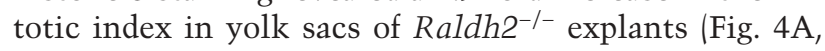
second row). Colocalization of phosphohistone-3 (green) with VE-Cadherin (VE-Cad, red) on sections (Fig. 4A) revealed that the proliferating cells were predominantly endothelium (arrows). TUNEL assays of yolk sacs from wild-type explants demonstrated that $3.4 \pm 2.0 \%$ of visceral endodermal and $28.7 \pm 6.5 \%$ of mesodermal cells were apoptotic (Fig. 4A, fourth row, black arrows). In

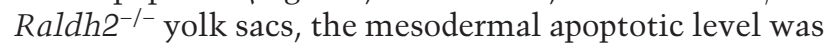
similar to that of wild type $(28.9 \pm 8.1 \%)$; however, apoptosis in the visceral endoderm was increased to $62.5 \pm 16.1 \%$ (Fig. 4A, fourth row, white arrows), indicating that RA is required for visceral endoderm survival. Furthermore, in untreated wild-type yolk sacs, Fn deposition was evident between the visceral endoderm and mesoderm (Fig. 4A, bottom row, arrows). As seen in vivo (Fig. 2D), Fn deposition between the mesoderm and visceral endoderm was decreased in untreated Raldh2 $2^{-/-}$ yolk sac explants.
Treatment of Raldh2 $2^{-/-}$explants with increasing concentrations of RA $(3,30,300 \mathrm{ng} / \mathrm{mL})$ progressively rescued vascular remodeling. Higher concentrations of RA had teratological effects, decreasing overall viability of

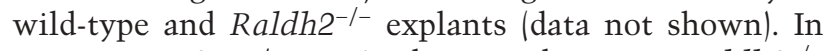
response to $3 \mathrm{ng} / \mathrm{mL} \mathrm{RA}$, the vasculature in Raldh2 ${ }^{-/}$ yolk sacs (Fig. 4B, right column) was remodeled to wildtype levels. Furthermore, treatment of Raldh2 ${ }^{-/-}$explants with RA restored cell cycle control as demonstrated by immunostaining on whole-mount and sections for phosphohistone-3 (Fig. 4B, middle and bottom rows). Treatment with EtOH (vehicle) did not restore vascular patterning in Raldh2 $2^{--}$explants and, at higher concentrations, decreased survival of wild-type and Raldh2 ${ }^{-/-}$explants (data not shown). These findings indicate that the embryo culture system recapitulates in vivo development. Thus, this system was used to elucidate the biological importance of regulatory factors downstream of RA signaling during vascular development.

\section{TGF- $\beta 1$ and Fn rescue Raldh2 $2^{-/}$vascular defects in vitro}

TGF- $\beta 1$ and Fn were identified as downstream targets of RA; thus, we sought to determine whether either could rescue the Raldh2 ${ }^{-/-}$yolk sac vascular defects. We found that exposure to $10 \mathrm{ng} / \mathrm{mL}$ TGF- $\beta 1$ induced vascular re- 
modeling in yolk sacs of Raldh2 $2^{-/-}$explants (Fig. 5A, right column), as evidenced by large vessel formation and capillary remodeling. Whole-mount and section immunostaining for phosphohistone-3 indicated that TGF$\beta 1$ decreased endothelial cell proliferation in Raldh2 ${ }^{-/-}$ yolk sac, but not to wild-type levels (Fig. 5A, second and third rows). Furthermore, treatment with TGF- $\beta 1$ restored Fn deposition between the visceral endoderm and mesoderm (Fig. 5A, bottom row), indicating that Fn production is downstream of TGF- $\beta 1$ signaling. Treatment with vehicle alone in this and all culture experiments had no effect on vessel formation or cell proliferation in wild-type or Raldh2 ${ }^{-/-}$explants (data not shown).

Treatment of Raldh2 $2^{-/-}$explants with $100 \mu \mathrm{g} / \mathrm{mL}$ soluble Fn enabled the initiation of vascular remodeling and the formation of large vessels in Raldh2 $2^{-/}$explants (Fig. 5B, right column). Fn also decreased endothelial cell proliferation in Raldh2 ${ }^{-/-}$explants (Fig. 5B, second and third rows) and decreased apoptosis in the visceral endoderm $(6.3 \pm 2.4 \%)$ to levels similar to that in Fn-treated wild-type explants $(6.6 \pm 0.5 \%$; Fig. 5B, fourth row). Furthermore, Fn deposition was restored in Raldh2 ${ }^{-/-}$explants by culture with exogenous Fn (Fig. 5B, bottom row, arrows). Histological sections confirmed formation of large remodeled vessels in Fn-treated Raldh2 ${ }^{-/-}$yolk

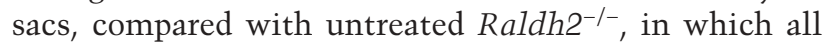
vessels were the same size and smaller in diameter (data not shown). These results indicate that Fn is a key downstream target of RA signaling, which mediates endothe- lial cell cycle control, visceral endoderm survival and function, vascular remodeling, and mural cell recruitment.

\section{Regulation of endothelial cell proliferation involves balanced signaling via integrins $\alpha 5$ and $\alpha \mathrm{V}$}

The regulation of endothelial cell proliferation by ECM proteins is mediated by integrin receptors $\alpha 5 \beta 1$, which is the predominant receptor for Fn, and $\alpha v \beta 3$, which is the principal receptor for vitronectin $(\mathrm{Vn})$. Fn-mediated signaling via $\alpha 5 \beta 1$ suppresses endothelial cell proliferation, which is necessary for lumen formation and the establishment of functional networks (Baldwin 1996). Alternatively, endothelial-expressed integrin $\alpha v \beta 3$ interacts with the VEGF-A pathway, increasing the phosphorylation of Flk-1 and inducing proliferation through ERK1 and ERK2 (Soldi et al. 1999). We hypothesized that balanced interactions between endothelial cells through integrins $\alpha 5$ and $\alpha \mathrm{v}$ with these ECM components either promote or suppress endothelial cell proliferation and maturation. To test this hypothesis, we first investigated the expression pattern of these integrin receptors in wild-type and Raldh2 ${ }^{-/-}$mutants. Integrin $\alpha 5$ transcript (Fig. 6A) and protein (Fig. 6B, top row) levels were decreased in E8.5 Raldh2 ${ }^{-/-}$yolk sacs compared with wild type. Feeding RA to pregnant females from E7.5-E8.5 restored both transcript (Fig. 6A) and protein (Fig. 6B, bottom row) expression of $\alpha 5$. Similarly, in embryo culture explants, $\alpha 5$ protein expression was decreased in
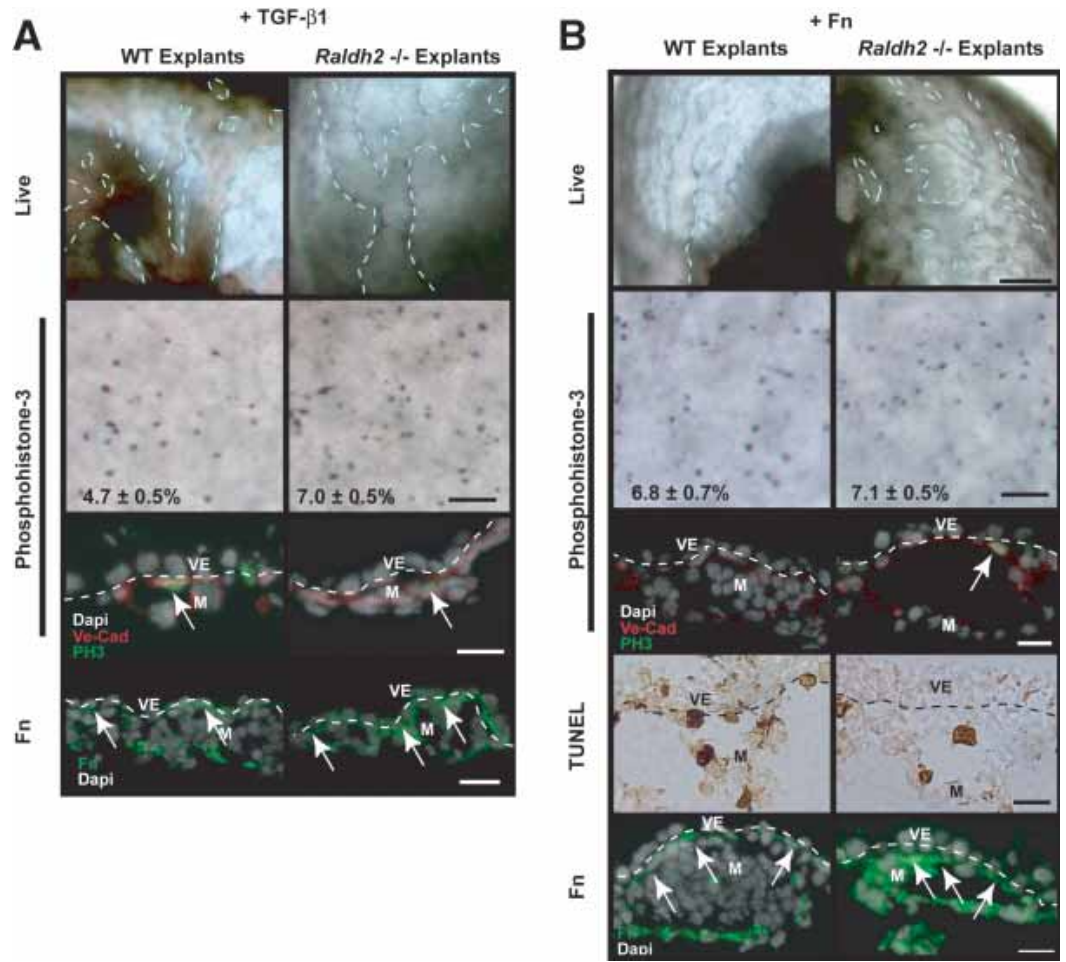

Figure 5. TGF- $\beta 1$ and Fn rescue Raldh2-/- vascular defects in vitro. (A) Treatment of Raldh2-/and wild-type (WT) embryo explants with $10 \mathrm{ng} /$ $\mathrm{mL}$ TGF- $\beta 1$ for $48 \mathrm{~h}$ initiated vascular remodeling in Raldh2-/- explants (top row). Detection of proliferating cells by whole-mount (middle row; bar $100 \mu \mathrm{m}$ ) immunostaining of yolk sacs with antiphosphohistone-3 and immunofluorescence (bottom row; bar $25 \mu \mathrm{m}$ ) with antiphosphohistone-3 (green) and VE-Cad (red) revealed that TGF- $\beta 1$ decreased endothelial cell proliferation in Raldh2 $2^{-/-}$explants but not to wild-type levels. Treatment with TGF- $\beta 1$ also restored Fn deposition between the visceral endoderm (VE) and mesoderm $(\mathrm{M})$ as demonstrated by immunofluorescence. (B) Treatment with $100 \mu \mathrm{g} / \mathrm{mL}$ soluble Fn rescued vascular remodeling in yolk sac of Raldh2 $2^{-1-}$ explants (top row; bar, $100 \mu \mathrm{m}$ ). Whole-mount immunostaining of yolk sac tissues (second row; bar, $100 \mu \mathrm{m}$ ) with antiphosphohistone-3 and immunofluorescence of yolk sac sections (third row; bar, $25 \mu \mathrm{m}$ ) with antiphosphohistone-3 (green) and VE-Cad (red) revealed that Fn rescued endothelial cell cycle control in Raldh2 ${ }^{-1-}$ explants to that of wild-type levels. TUNEL assay (fourth row; bar, $25 \mu \mathrm{m}$ ) demonstrated that Fn reduced the level of apo-

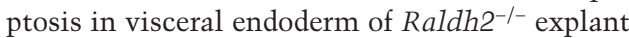

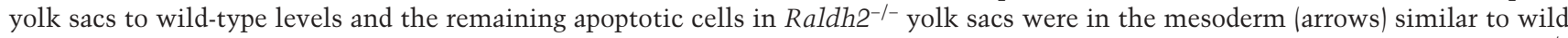
type. (Bottom row) Detection of Fn protein by immunofluorescence of yolk sac sections demonstrated that treatment of Raldh2 ${ }^{-/}$ with soluble Fn restored Fn deposition between the visceral endoderm and mesoderm layers of the yolk sac (arrows). 
Bohnsack et al.

Figure 6. Endothelial cell proliferative control is regulated by extracellular matrix proteins via integrin $\alpha 5$ and integrin $\alpha \mathrm{v}$. (A) sqRT-PCR analysis of E8.5 Raldh2 ${ }^{-/-}$and wild-type (WT) yolk sacs revealed down-regulation of integrin $\alpha 5$ transcript, but no change in $\beta 1, \alpha \mathrm{V}$, or $\beta 3$ levels. Feeding RA to pregnant females from E7.5-E8.5 restored $\alpha 5$ transcript levels in Raldh2 ${ }^{-1-}$ yolk sacs. HPRT was used as an internal control. (B) Immunofluorescence demonstrated that integrin $\alpha 5$ protein is decreased in control fed E8.5 Raldh2 $2^{-/-}$yolk sacs compared with wild type (WT; top row), but protein expression was restored by feeding RA to pregnant females from E7.5-E8.5 (bottom row). There were no differences in protein levels of $\beta 1$ (second row), $\alpha \mathrm{v}$ (third row), or $\beta 3$ (fourth row) in E8.5 Raldh2 ${ }^{-/-}$yolk sacs compared with wild type. $(C)$ Western blot analyses of E8.5 Raldh2 ${ }^{-/-}$and wild-type (WT) yolk sac protein demonstrated increased phosphorylation of ERK1/2 at Tyr 204 (top row) in mutant yolk sacs compared with wild type. Conversely, protein levels of p21 (third row) were decreased in Raldh2-/yolk sacs. Total ERK (second row), and actin (bottom row) were used as loading controls. $(D)$ Immunofluorescence of embryo culture sections revealed that integrin $\alpha 5$ protein, which was decreased in control treated Raldh2 ${ }^{-/-}$explants (top row), was restored by treatment with $3 \mathrm{ng} / \mathrm{mL}$ RA (middle row) and $100 \mu \mathrm{g} / \mathrm{mL}$ Fn (bottom row). (E) Western blot analyses of yolk sacs from embryo culture explants demonstrated that phosphorylation of ERK1/2 (Tyr 204), which were increased in untreated Raldh2 $2^{-1-}$ mutants, were restored to wild-type levels by treatment with $3 \mathrm{ng} /$ $\mathrm{mL}$ RA and $100 \mu \mathrm{g} / \mathrm{mL}$ Fn. Protein levels of p21 were decreased in untreated Raldh2-/- explants but restored by treatment with RA. (F) Blocking antibodies to integrin $\alpha 5$ (middle column) or integrin $\alpha \mathrm{v}$ (right column) inhibited vascular remodeling in $40 \%$ of wild-type explants in whole embryo culture (top row; bar, $100 \mu \mathrm{m}$ ). Whole-mount immunostaining (second row; bar, $100 \mu \mathrm{m}$ ) with antiphosphohistone-3 and immunofluorescence (third row; bar, $25 \mu \mathrm{m}$ ) with antiphosphohistone-3 (green) and VE-Cad (red) revealed that blocking integrin $\alpha 5$ signaling increased endothelial cell proliferation. Conversely, inhibiting integrin $\alpha \mathrm{v}$ resulted in decreased proliferation. TUNEL assay (bottom row) demonstrated no differences in apoptosis in the mesoderm (arrows) and visceral endoderm in control and $\alpha 5$ or $\alpha \mathrm{v}$ antibody treated explants.

control treated Raldh2 ${ }^{-/-}$explants, but restored by treatment with $3 \mathrm{ng} / \mathrm{mL}$ RA or $100 \mu \mathrm{g} / \mathrm{mL}$ Fn (Fig. 6D). No changes in transcript or protein levels of integrin $\beta 1, \alpha \mathrm{V}$, or $\beta 3$ were detected by sqRT-PCR and immunohistochemistry in E8.5 Raldh2-/- versus wild-type yolk sacs (Fig. 6A,B). In addition, there was no difference in Vn expression in Raldh2 $2^{-1-}$ and wild-type yolk sacs (data not shown).

The specific decrease in integrin $\alpha 5$ expression suggests that increased endothelial cell proliferation in Raldh2 $2^{-/-}$yolk sacs is due to an imbalance between integrin $\alpha 5 \beta 1$ and integrin $\alpha v \beta 3$ signaling. To investigate the downstream intracellular pathways, we determined the level of phosphorylation of ERK1/2 (Tyr 204) in E8.5 yolk sacs and in embryo culture explants. ERK1/2 was hyperphosphorylated in E8.5 Raldh2 $^{-/-}$yolk sacs (Fig. 6C) as well as in control treated mutant explant yolk sacs (Fig. 6E). Treatment with RA or Fn decreased ERK1/2 phosphorylation to wild-type levels (Fig. 6E). Conversely, the cell cycle inhibitor, p21 was decreased

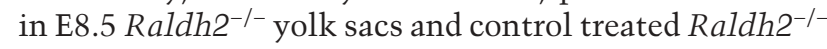
explants (Fig. 6C,E), but was restored by exogenous RA. Expression of p21, however was not restored by exogenous Fn (Fig. 6E). These results suggest that in Raldh2 $2^{-/-}$mutant yolk sacs, increased endothelial cell proliferation is secondary to $\alpha \mathrm{v} \beta 3$-mediated activation of the MAPKs, ERK1/2.

To confirm the regulation of endothelial cell prolifera- 
tion by integrins $\alpha 5 \beta 1$ and $\alpha \mathrm{v} \beta 3$ in vivo, blocking antibodies against specific $\alpha$ subunits were used in embryo culture. In control cultures, all wild-type explants (12/ 12) showed extensive remodeling after $48 \mathrm{~h}$. Approximately $40 \%$ (9/21) of wild-type explants treated with anti-integrin $\alpha 5$ antibodies lacked substantial vascular plexus remodeling in the yolk sac (Fig. 6F, middle column). Similarly $40 \%$ (7/19) of anti-integrin $\alpha v$-treated wild-type explants had decreased remodeling (Fig. 6F, right column). Blocking $\alpha 5$ increased endothelial cell proliferation over control levels as evidenced by wholemount and immunohistochemical detection of phosphohistone-3 (Fig. 6F, second and third rows). Conversely, blocking $\alpha \mathrm{v}$ decreased proliferation below control levels. Inhibition of $\alpha 5$ or $\alpha \mathrm{v}$ did not alter apoptosis levels in the mesoderm (Fig. 6F, bottom row, arrows) or visceral endoderm. These results indicate that control of endothelial cell proliferation is the result of balanced Fn-mediated integrin signaling; $\alpha 5 \beta 1$ inhibits proliferation and $\alpha v \beta 3$ increases proliferation through activation of MAPK pathway. Decreased expression of $\alpha 5$ in Raldh2 $^{-/-}$mutants favors enhanced $\alpha \mathrm{v}$-mediated endothelial cell growth.

\section{Endoderm-derived signals do not regulate endothelial cell proliferation but collectively modulate vascular remodeling}

Our results also indicated that VEGF-A, IHH, and bFGF, produced by visceral endoderm, are indirect targets of
RA because they are down-regulated secondary to decreased visceral endoderm integrity and function. We investigated whether any of these factors could rescue the vascular defects in Raldh2 ${ }^{-/-}$yolk sacs. Treatment with $50 \mathrm{ng} / \mathrm{mL}$ VEGF-A ${ }_{165}$ did not restore remodeling in Raldh2 ${ }^{-1-}$ yolk sacs (Fig. 7A, right column), as the vessels were uniform in diameter and intervascular spaces were evenly distributed. Furthermore, phosphohistone-3 immunostaining of VEGF-A $165^{\text {-treated }}$ Raldh2 $^{-/-}$revealed a twofold increase in endothelial cell proliferation, similar to that in untreated mutant explants (Fig. 7A, second and third rows, arrows). TUNEL analysis demonstrated that $48.0 \pm 28.0 \%$ of visceral endodermal cells were apoptotic in VEGF-A V $_{165}$-treated mutant explant yolk sacs with to $2.8 \pm 2.6 \%$ in similarly treated wild-type explants (Fig. 7A, bottom row, white arrows). Raldh2-/- explants treated with $1 \mu \mathrm{g} / \mathrm{mL}$ cholesterolmodified IHH or $100 \mathrm{ng} / \mathrm{mL}$ recombinant human bFGF similarly exhibited no rescue in vascular remodeling (data not shown). These results indicate that VEGF-A $\mathrm{A}_{165}$, $\mathrm{IHH}$, or bFGF can not individually restore the vascular

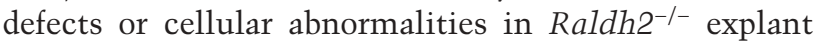
yolk sacs.

Both in vivo and explant studies demonstrated decreased visceral endoderm integrity in Raldh2 ${ }^{-/-}$yolk sacs, implying that supplementation of only one factor may be inadequate to restore vascular remodeling. Thus, we subjected cultured embryos to combined treatment with VEGF-A $165(50 \mathrm{ng} / \mathrm{mL}), \mathrm{IHH}(1 \mu \mathrm{g} / \mathrm{mL})$, and bFGF $(100 \mathrm{ng} / \mathrm{mL})$, which initiated vascular remodeling in
A

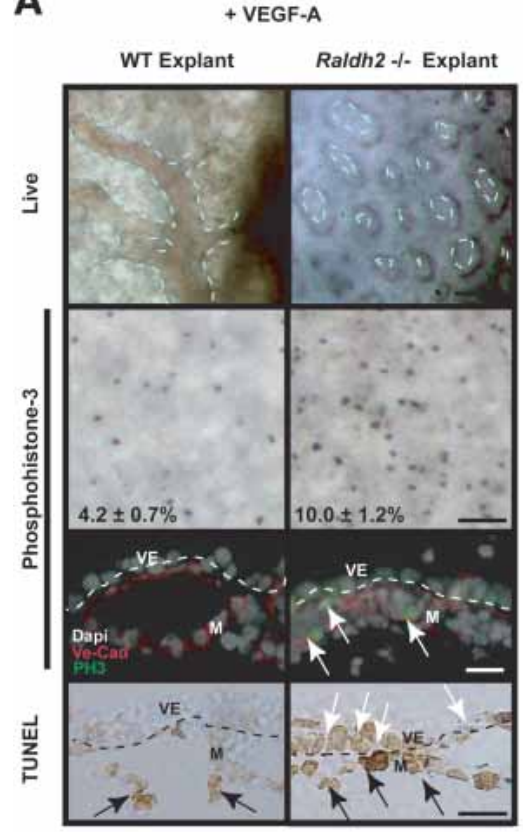

B

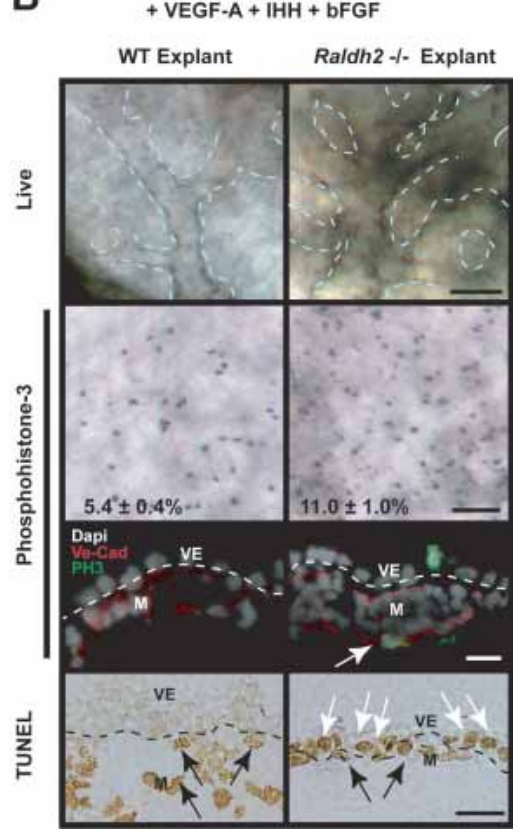

Figure 7. Visceral endoderm factors are required for vascular remodeling, but not endothelial proliferative control. (A) Treatment with $50 \mathrm{ng} / \mathrm{mL}$ VEGF- $\mathrm{A}_{165}$ in whole embryo culture failed to induce vascular remodeling in Raldh2 $2^{--}$explant yolk sacs (top row; bar, $100 \mu \mathrm{m})$. Whole-mount immunostaining of yolk sac tissues with antiphosphohistone-3 (second row; bar, $100 \mu \mathrm{m}$ ) and immunofluorescence of yolk sac sections (third row; bar, $25 \mu \mathrm{m}$ ) with antiphosphohistone-3 (green) and VE-Cad (red) demonstrated that Raldh2-/- explants treated with VEGF-A ${ }_{165}$, had a twofold increase in proliferating endothelial cells (arrows) compared with wild type (WT). TUNEL analyses of yolk sac sections (bottom row; bar, $25 \mu \mathrm{m}$ ) revealed that VEGF- $\mathrm{A}_{165}$ treated Raldh2 ${ }^{--}$explants had a 10 -fold increase in apoptosis in visceral endoderm (VE, white arrows) but no change in the mesoderm $(\mathrm{M}$, black arrows). (B) Treatment with $50 \mathrm{ng} / \mathrm{mL}$ VEGF-A $\mathrm{A}_{165}+1 \quad \mathrm{\mu g} / \mathrm{mL} \quad \mathrm{IHH}+100 \quad \mathrm{ng} / \mathrm{mL}$ bFGF induced vascular remodeling in Raldh2-/- explant yolk sac (top row; bar, 100 $\mu \mathrm{m})$. Whole-mount immunostaining of yolk sac tissues with antiphosphohistone-3 (second row; bar, $100 \mu \mathrm{m}$ ) and immunofluorescence with antiphosphohistone-3 (green) and

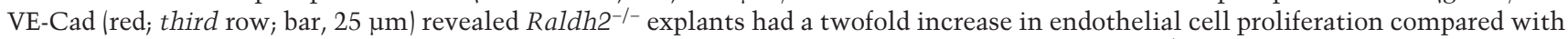
wild type. TUNEL assay of yolk sac sections (bottom row; bar, $25 \mu \mathrm{m}$ ) demonstrated that Raldh2-/- explants treated with $50 \mathrm{ng} / \mathrm{mL}$ rh-VEGF-A $\mathrm{A}_{165}+1 \mathrm{\mu g} / \mathrm{mL} \mathrm{IHH}+100 \mathrm{ng} / \mathrm{mL}$ bFGF had a 10 -fold increase in apoptosis in visceral endoderm (white arrows), similar to untreated Raldh2 $2^{--}$explants. 
Raldh2 $2^{-/-}$explant yolk sacs (Fig. 6B, right column); however, the large vessels were dilated and not wild type. Immunostaining for phosphohistone-3 revealed a twofold increase in proliferating endothelial cells in VEGF-A $\mathrm{A}_{165}+\mathrm{IHH}+$ bFGF-treated Raldh2 ${ }^{-/-}$explant yolk sacs (Fig. 7B, second and third rows, arrows), indicating that control of endothelial cell proliferation was not restored. TUNEL analysis showed that $60.9 \pm 0.9 \%$ cells in the visceral endoderm in VEGF-

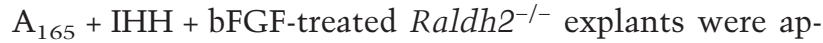
optotic compared with $2.0 \pm 3.4 \%$ in similarly treated wild type, indicating that visceral endoderm integrity was not rescued (Fig. 7B, bottom row, arrowheads). Thus, visceral endoderm derived factors can collectively modu-

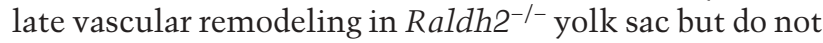
restore endothelial cell proliferation or visceral endoderm survival.

\section{Discussion}

Vascular induction and remodeling are complex processes that involve paracrine and autocrine signals, cellcell communication, and cellular interactions with the ECM. The fact that numerous genetically engineered mutant mice share a common phenotype, lack of capillary plexus remodeling, indicates that this process re- quires a convergence of multiple pathways (RA, TGF- $\beta$, Fn, VEGF-A, IHH, and bFGF). Each pathway has been independently shown to play a role in vascular morphogenesis, but interactions between, and a hierarchy among, these pathways has not been defined and is the focus of these studies.

It is important to note that defects in vascular remodeling can also result from altered systemic circulation secondary to hematopoietic defects or cardiac malformation. Therefore, in the current studies, we focused our molecular analyses of vascular morphogenesis at the early somitic stage, prior to the onset of cardiac function and systemic blood flow (approximately eight somites). Thus, we are confident that the defects in vascular development reported are primarily due to disrupted vascular cell signaling and not secondary to cardiac malformations or hemodynamic alterations, which can be confounding problems at later stages of development.

Previously we determined, by using RA-deficient (Raldh2 $\left.{ }^{-/-}\right)$mutants, that RA controls endothelial cell growth via induction of $\mathrm{p} 21$, which occurs in a biphasic manner; an early peak suggesting direct transcriptional or posttranscriptional regulation, and an increase several days later suggesting that other pathways downstream of RA signaling may contribute to endothelial cell growth control and vascular remodeling (Lai et al. 2003). Thus,
Figure 8. RA regulation of reciprocal interactions between the visceral endoderm and mesoderm that control endothelial cell growth and vascular remodeling. $(A)$ In the wild-type (WT) yolk sac, maternally derived retinol is taken up by the visceral endoderm from the trophoblast sinuses, where it is converted into active RA by Raldh2. RA targets endothelial cells within the mesoderm through RAR $\alpha 1$ and RAR $\alpha 2$ and promotes Fn transcription and production via the TGF- $\beta 1$ pathway. ECM proteins dually regulate endothelial cell proliferation through different integrin receptors. Integrin $\alpha \mathrm{v} \beta 3-\mathrm{Vn}$ interactions induce proliferation by enhancing Flk-1 phosphorylation and activation of ERK1/2. Conversely, integrin $\alpha 5 \beta 1-F n$ interactions inhibit endothelial cell proliferation. Fn deposition between the visceral endoderm and mesoderm layers is also required for visceral endoderm maintenance and continued production of factors essential for vascular remodeling ( $\mathrm{qk}$, VEGF-A, IHH, bFGF) and barrier function (Cldn7). (B) In

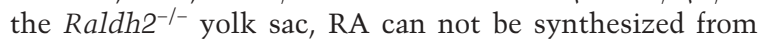
retinol resulting in down-regulation of TGF- $\beta$ and Fn. Furthermore, integrin $\alpha 5$ is specifically decreased leading to increased $\alpha \mathrm{V}-\mathrm{Vn}$-mediated activation of ERK1/2 and uncontrolled endothelial cell proliferation. Reduced Fn deposition between mesoderm and visceral endoderm also results in increased apoptosis of extraembryonic visceral endoderm, which is concomitant with decreased production of soluble signals required for vascular remodeling.

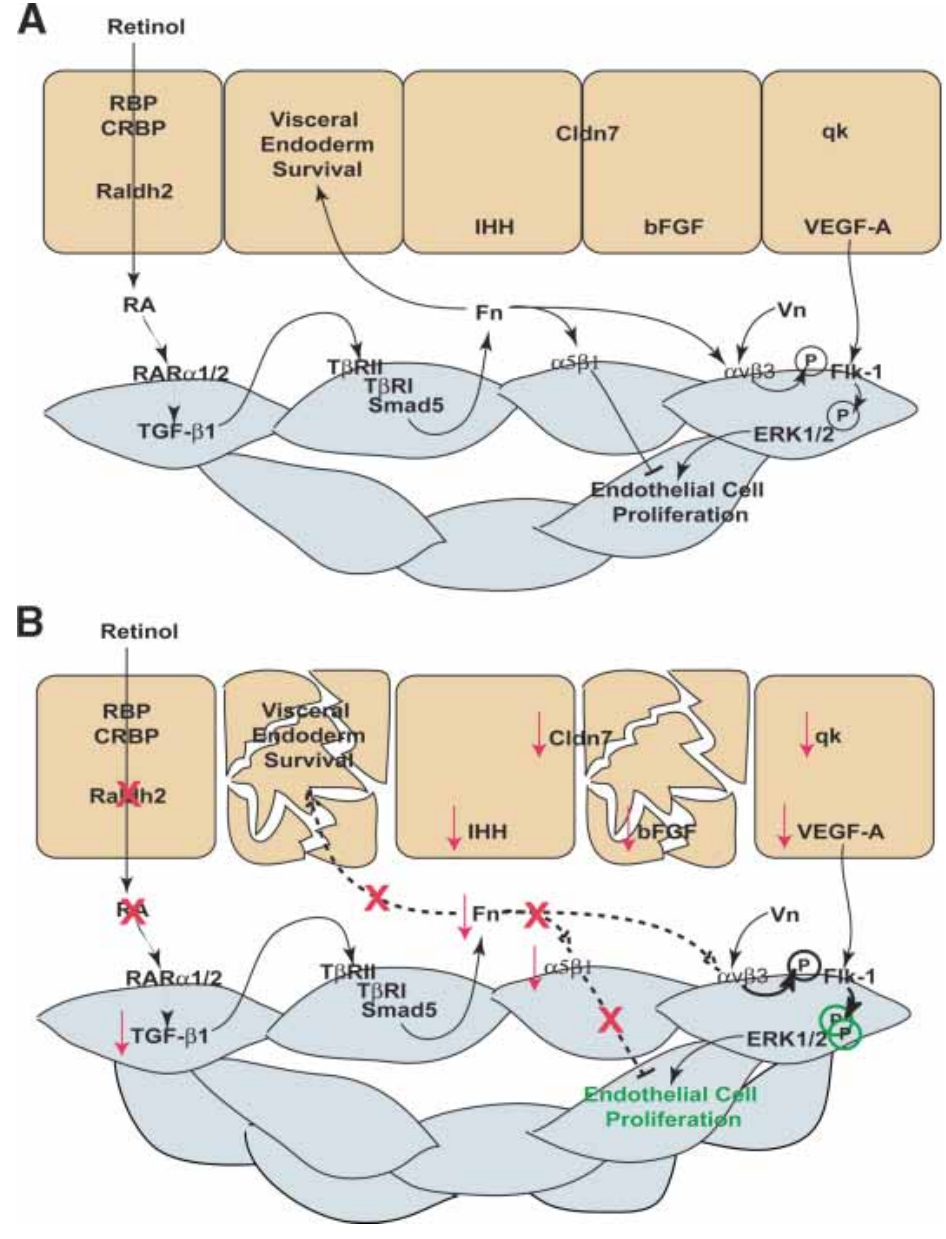


we investigated whether other signaling pathways implicated in the control of these processes were dysregulated in Raldh2 $2^{-/-}$mutants.

We found that the absence of RA led to suppression of TGF- $\beta 1$ and Fn production in endothelial cells and down-regulation of VEGF-A, IHH, and bFGF in visceral endoderm (Fig. 8B). These alterations in gene expression correlated with enhanced endothelial cell growth, decreased visceral endoderm survival, and lack of capillary plexus remodeling. Importantly, all of these defects in the Raldh2 ${ }^{-1-}$ mutants were rescued with RA in vivo and in embryo culture. Therefore, we took advantage of the in vitro rescue system to elucidate the hierarchy of these signaling pathways downstream of RA and define the cellular function of each in the control of endothelial cell growth and vascular remodeling.

We determined that TGF- $\beta 1$ and Fn decreased endothelial cell proliferation and restored vascular remodeling and visceral endoderm survival in Raldh2 $2^{--}$mutants. Although RA regulation of TGF- $\beta 1$ expression has not been previously described, there are multiple RA responsive elements in the promoter (A. Cooney, B. Bohnsack, and K. Hirschi, unpubl.), suggesting direct transcriptional regulation of TGF- $\beta 1$ by RA. Subsequent TGF- $\beta 1$ regulation of $F n$ has been described in numerous cell types (Ignotz and Massague 1986; Ignotz et al. 1987), including endothelial cells. Furthermore, mutants with a dominant-negative TGF- $\beta 1$ type II receptor (T $\beta$ RII; Goumans et al. 1999) and mice lacking T $\beta R I$ (Larsson et al. 2001) exhibited decreased Fn deposition between yolk sac visceral endoderm and mesoderm. Interestingly, we also found that mice lacking Smad5, which have a vascular phenotype similar to the T $\beta R I$ and T $\beta$ RII mutants (Chang et al. 1999), exhibited decreased Fn expression (B.L. Bohnsack, unpubl.). The overlapping phenotypes of TGF- $\beta 1$ - and RA-deficient mutants corroborate our embryo culture rescue studies and suggest that a major role of RA in vascular morphogenesis is regulation of TGF$\beta$-mediated Fn deposition, which is required for normal endothelial cell growth and vascular remodeling.

Fn has been shown to signal through multiple integrin receptors, $\alpha_{3} \beta_{1}, \alpha_{4} \beta_{1}, \alpha_{5} \beta_{1}, \alpha_{8} \beta_{1}, \alpha_{\mathrm{v}} \beta_{1}, \alpha_{\mathrm{v}} \beta_{3}, \alpha_{\mathrm{v}} \beta_{6}, \alpha_{\mathrm{IIb}} \beta_{3}$ (Yang et al. 1999), and exert diverse downstream effects depending on receptor and cell type. Angioblasts in the yolk sac express $\alpha_{5} \beta_{1}$ and $\alpha_{\mathrm{v}} \beta_{3}$, and their critical role in vascular remodeling is evidenced by the phenotype of $\mathrm{Fn}^{-/-}$or $\mathrm{\alpha}_{5}{ }^{-/-}$mice (George et al. 1993, 1997; Yang et al. 1993; Francis et al. 2002).

Numerous studies have investigated the regulation of endothelial cell proliferation by ECM proteins and their integrin receptors. Integrin $\alpha v \beta 3$ when bound to Vn enhances VEGF-A signaling through phosphorylation of Flk-1 and activation of the downstream MAPK signaling pathway, thereby promoting proliferation (Soldi et al. 1999). Integrin $\alpha 5 \beta 1$, on the other hand, does not interact with VEGF-A or bFGF signaling pathways, and its binding to Fn is suggested to be important for endothelial cell maturation and tube formation (Baldwin 1996). Our data suggest that endothelial cell proliferative control during vascular morphogenesis is the result of a balancing act between ECM proteins and their integrin receptors. Integrin $\alpha v \beta 3$ promotes proliferation and migration through cross-talk with VEGF-A and activation of MAPK pathway. Integrin $\alpha 5 \beta 1$ inhibits proliferation to promote maturation. In Raldh2 $2^{-/-}$mutant yolk sacs, increased endothelial cell proliferation is secondary to a specific decrease in integrin $\alpha 5$ and Fn in the presence of unaltered levels of integrin $\alpha v \beta 3$ and Vn, resulting in hyperphosphorylation and activation of the MAPKs ERK1 and ERK2.

Fn deposition not only rescued endothelial cell proliferation defects in Raldh2 $2^{-/-}$mice but also restored endodermal survival. The expression of Fn-binding integrins in yolk sac visceral endoderm has not been investigated; therefore, survival pathways activated by Fn in these cells are undetermined. In other cell types, however, Fn-activated integrin signaling pathways promote cell survival. For example, in endothelial cells, Fn induces phosphorylation of EGF receptor, resulting in activation of MAPK and cell survival (Moro et al. 1998). In vitro studies using F9 teratocarcinoma cells have demonstrated that $\beta_{1}$ and $\alpha_{5}$ are expressed in visceral endoderm monolayers (Morini et al. 1999), and we find expression of these two subunits as well as $\beta 3$ in the visceral endoderm. Blocking $\alpha 5$ signaling however, had no effect on visceral endoderm integrity, suggesting that survival pathways are downstream of alternate integrin receptors.

In summary, our data from these and previous studies collectively indicate that the control of endothelial cell proliferation and vascular plexus remodeling during vascular morphogenesis are independently regulated. RA is integral to both processes in that it regulates endothelial cell growth directly via regulation of p21 as well as indirectly via TGF- $\beta$-induced Fn, which interacts with integrin $\alpha 5$ to suppress proliferation. RA also indirectly regulates visceral endoderm survival and production of soluble signals (VEGF-A, Ihh, bFGF) required for vascular remodeling. Thus, the control of RA production and degradation is critical for the regulation of signaling pathways required for normal vascular development.

\section{Materials and methods}

\section{Genotyping and tissue processing}

Targeted disruption of Raldh2 gene (Niederreither et al. 1999) and genotyping were performed as described (Lai et al. 2003). Timed pregnancies were obtained by paired matings; morning of the vaginal plug was considered E0.5. Tissues were obtained at specified times, and embryos were staged (Downs and Davies 1993). For frozen sections, tissues were mounted in O.C.T. Compound (Tissue-Tek), flash-frozen in liquid nitrogen, and sectioned at $10 \mu \mathrm{m}$. Tissues used for whole-mount analyses were fixed in $4 \%$ paraformaldehyde (PFA) overnight at $4^{\circ} \mathrm{C}$. RA feeding experiments were carried out as previously described (Lai et al. 2003).

\section{Endoderm-mesoderm dissections}

The extraembryonic region of early-late allantoic bud stage (E7.5) embryos from CD1 wild-type females was dissected free 
of deciduas, ectoplacental cone, and Reichert's membrane and digested in $0.5 \%$ porcine pancreatic trypsin (Sigma), $0.25 \%$ porcine pancreatin (Sigma) in PBS for $25 \mathrm{~min}$ on ice. Mesoderm was removed from visceral endoderm with tungsten and glass needles by using a dissecting microscope.

\section{$S q R T-P C R$}

Tissues from E5.5 embryos, the extraembryonic regions of early streak (E6.5) or E7.5 embryos, or yolk sacs from five- to sevensomite stage (E8.5) embryos were dissected free of ectoplacental tissues, and RNA was extracted by using TRIzol Reagent (Invitrogen). One $\mu$ g of yolk sac RNA was reverse transcribed with random primers (Invitrogen) and Superscript Reverse Transcriptase II (Invitrogen) for $50 \mathrm{~min}$ at $42^{\circ} \mathrm{C}$ and $15 \mathrm{~min}$ at $72^{\circ} \mathrm{C}$. One-twentieth of the RT reaction was PCR-amplified by using Taq polymerase (Invitrogen) and specific primers (sequences available upon request). All primer sets were run at optimized annealing temperature, within determined linear range and with no RT controls. HPRT was used as an internal control for sq comparison. Each RT-PCR experiment was performed with four to five separate RNA isolations.

\section{In situ hybridization}

DIG RNA Labeling kit (SP6/T7; Roche) was used to make digoxigenin-UTP-labeled antisense and sense RNA probes. Briefly, each cDNA was generated by RT-PCR, cloned into the pGEM-TEasy Vector (Promega), sequence verified, and in vitro transcribed. Labeling efficiency was measured by chemiluminescent dot blot with DIG Nucleic Acid Chemiluminscent Detection kit (Roche). E8.5 wild-type and Raldh2 ${ }^{-/-}$frozen tissue sections were fixed in 4\% PFA for $20 \mathrm{~min}$ at room temperature (RT), washed in PBS, digested with Proteinase K $(5 \mu \mathrm{g} / \mathrm{mL}$; Research Products International) for $5 \mathrm{~min}$ at RT, washed in PBS, and refixed in $4 \%$ PFA for $5 \mathrm{~min}$. Sections were washed in DEPC-treated $\mathrm{H}_{2} \mathrm{O}$ and acetylated with $0.25 \%$ acetic anhydride in $0.1 \mathrm{M}$ triethanolamine for $10 \mathrm{~min}$ at RT. Tissues were prehybridized in hybridization buffer $(50 \%$ formalin, $2 \times$ SSC, $2 \times$ Denhardt's solution, $10 \%$ dextran sulfate, $0.04 \%$ yeast tRNA, $0.025 \%$ salmon sperm DNA, $20 \mathrm{mM} \mathrm{DTT}$ ) for $1-3 \mathrm{~h}$ at $60^{\circ} \mathrm{C}$ followed by hybridization with specific RNA probes in hybridization buffer $(0.5-1 \mu \mathrm{g} / \mathrm{mL})$ overnight at $55^{\circ} \mathrm{C}$. Sections were washed for $10 \mathrm{~min}$ at $60^{\circ} \mathrm{C}$ in $1 \times$ SSC and $1.5 \times$ SSC followed by washes in $2 \times \mathrm{SSC}$ for $20 \mathrm{~min}$ at $37^{\circ} \mathrm{C}$ and $0.2 \times \mathrm{SSC}$ for $30 \mathrm{~min}$ at $60^{\circ} \mathrm{C}$. Tissues were washed for $10 \mathrm{~min}$ with $0.1 \%$ Tween-20 in PBS (PBS-Tween) at $60^{\circ} \mathrm{C}$ then at RT and then washed with $0.1 \%$ Triton X-100, $0.2 \%$ BSA in PBS (PBT) for 15 min at RT. Detection of digoxigenin-labeled probes was carried out with DIG Nucleic Acid Detection Kit (Roche). Slides were incubated with blocking buffer ( $1 \%$ blocking reagent in Maleic Acid buffer [MAB; $0.1 \mathrm{M}$ Maleic acid, $0.15 \mathrm{M} \mathrm{NaCl}$ at $\mathrm{pH} 7.5]+2 \%$ normal sheep serum) for $2-3 \mathrm{~h}$ at RT and incubated overnight at $4{ }^{\circ} \mathrm{C}$ with antidigoxigenin AP-conjugated secondary antibodies diluted 1:1000 in blocker. Sections were washed three times in PBT for 30 min at RT and equilibrated in detection buffer (Tris$\mathrm{HCl}, \mathrm{NaCl}$ at $\mathrm{pH}$ 9.5). Transcripts were detected with $\mathrm{NBP} /$ BCIP in detection buffer (1:50). Prehybridization, secondary blocking, and developing time were optimized for each probe.

\section{Whole-mount immunostaining and immunohistochemistry}

Whole-mount analyses were carried out as previously described (Lai et al. 2003). For quantification of cell proliferation, the numbers of phosphohistone-3 positive and DAPI-stained nuclei in each of four high-power fields was counted in three to four yolk sac samples; data represent the mean \pm standard error for each group.

For immunohistochemistry, tissue sections were fixed at $4{ }^{\circ} \mathrm{C}$ in $4 \%$ PFA for $30 \mathrm{~min}$ or acetone for $10 \mathrm{~min}$ and incubated with primary antibodies for $1 \mathrm{~h}$ at $\mathrm{RT}$ or $4^{\circ} \mathrm{C}$ overnight. Primary antibodies included: rabbit anti-RAR $\alpha$ (1:50, BioMol), rat antiICAM-2 (1:50, Becton Dickinson), mouse anti-TGF- $\beta 1$ (1:500, Genzyme), goat anti-Col I (1:10, Chemicon), rabbit anti-fibronectin (Fn; 1:500, Becton Dickinson), rabbit anti-VEGF-A (1:50, Neomarkers), rabbit antiphosphohistone-3 (1:100, Neomarkers), goat anti-VE-Cadherin (1:20, R \& D), rabbit anti-integrin $\alpha 5$ (1:100, Chemicon), rat anti-integrin $\beta 1$ (1:100, Chemicon), rabbit anti-integrin $\alpha \mathrm{v}(1: 50$, Santa Cruz), and rabbit anti-integrin $\beta 3$ (1:100, Chemicon). Sections were incubated with appropriate secondary antibody conjugated to Alexa fluorophore 488 or 594 (1:500, Molecular Probes) for $30 \mathrm{~min}$ at RT or biotinylated secondary antibodies (Vectastain Elite ABC kit; Vector) for $1 \mathrm{~h}$ at $\mathrm{RT}$, which were then detected with DAB or VIP /Vector Laboratories).

\section{TUNEL assay}

TUNEL assays were performed on frozen tissue sections by using a modification of a published protocol (Gavrieli et al. 1992). Tissue sections were fixed in 4\% PFA for $15 \mathrm{~min}$, washed in PBS, digested with $20 \mu \mathrm{g} / \mathrm{mL}$ proteinase K (Research Products International) for 7-12 min at RT, washed in PBS, and refixed in $4 \%$ PFA for $5 \mathrm{~min}$. Sections were equilibrated in $1 \times \mathrm{TdT}$ buffer (0.1 M potassium cacodylate, $2 \mathrm{mM} \mathrm{CoCl}_{2}, 0.25 \mathrm{mM} \mathrm{DTT}$ ) for $5 \mathrm{~min}$. Tissues were incubated with $\mathrm{TdT}$ ( $30 \mathrm{U}$; Invitrogen) and $10 \mu \mathrm{M}$ biotinylated d-UTP (Roche) in $1 \times$ TdT buffer for $1-2 \mathrm{~h}$ at $37^{\circ} \mathrm{C}$. Reaction was stopped with $2 \times$ SSC, and tissues were washed three times in PBS. Biotinylated DNA was conjugated to HRP by incubating with $\mathrm{ABC}$ reagent (Vectastain Elite $\mathrm{ABC}$ kit, Vector) for $30 \mathrm{~min}, \mathrm{DAB}$ was used as a colorimetric substrate to detect labeled DNA, and slides were coverslipped with DAPI. Negative $(-\mathrm{TdT})$ and positive (sections treated with DNAseI) controls were included in all analyses. For quantification of apoptotic cells, the numbers of DAB-stained positive and total DAPI-stained nuclei were counted in each of four highpower fields in three to four yolk sacs.

\section{Western blot analysis}

Western blot analyses were carried out as previously described (Lai et al. 2003). Total protein was isolated from pooled genotyped yolk sacs or from bovine aortic endothelial cells that were cultured in the presence of $1.0 \mu \mathrm{M}$ RA or $1 \mathrm{ng} / \mathrm{mL}$ human recombinant TGF- $\beta 1$ (R\&D) for 12-72 h. For blocking studies, neutralizing antibodies against TGF- $\beta 1$, TGF- $\beta 2$, and TGF- $\beta 3$ $(10 \mu \mathrm{g} / \mathrm{mL}$; kindly provided by Genzyme) were added in the presence of $1.0 \mu \mathrm{M}$ RA or $1 \mathrm{ng} / \mathrm{mL}$ TGF- $\beta 1$ for $48 \mathrm{~h}$. Primary antibodies were as follows: mouse anti-TGF- $\beta 1$ (1:250, Genzyme), rabbit anti-Fn (1:500, Becton Dickinson), goat anti-Col I (1:100, Chemicon), goat anti actin (1:1000, Santa Cruz), rabbit anti-VEGF-A (1:500, Chemicon), anti-tubulin (1:2000, Neomarkers), goat antiphospho Tyr 204 ERK (1:500, Santa Cruz), rabbit anti-ERK (1:1000, Santa Cruz), or mouse anti-p21 (1:100, Neomarkers) in 5\% nonfat dry milk in PBS-Tween.

\section{Whole mouse embryo culture}

E7.5 embryos were dissected in 10\% FBS in PBS; yolk sac integrity with the ectoplacental cone was maintained, and Reichert's membrane was removed. Embryos were placed in continuous gas $\left(5 \% \mathrm{O}_{2}, 5 \% \mathrm{CO}_{2}\right)$ rolling culture in $75 \%$ immedi- 
ately centrifuged rat serum (Harlan), Dulbeco's modified essential medium (DMEM; GIBCO), and glutamine (2 mM)penicillin (100 U/ml)-streptomycin $(100 \mu \mathrm{g} / \mathrm{mL}$; GIBCO). Media was changed after $24 \mathrm{~h}$, and embryos were analyzed at $48 \mathrm{~h}$. Only embryos in which the allantois fused to the ectoplacental cone were assessed for vascular morphology. For rescue experiments, RA (3, 30, $300 \mathrm{ng} / \mathrm{mL}$; Sigma) was suspended in $100 \%$ EtOH with a final vehicle concentration ranging from $0.003 \%$ to $0.3 \%$, human platelet derived TGF- $\beta 1$ (10 ng/mL; R\&D) was suspended in $4 \mathrm{mM} \mathrm{HCl}, 0.1 \%$ BSA, bovine soluble plasma $\mathrm{Fn}$ $\left(100 \mu \mathrm{g} / \mathrm{mL}\right.$; Invitrogen) was diluted in $4 \mathrm{mM} \mathrm{Na}_{2} \mathrm{PO}_{4}$, recombinant human VEGF-A (50 ng/mL; R\&D) was suspended in $0.1 \%$ BSA, recombinant human bFGF (100 ng/ml; R\&D) was suspended in $0.1 \%$ BSA and $1 \mathrm{mM} \mathrm{DTT}$, IHH $(1 \mu \mathrm{g} / \mathrm{mL}$, kindly provided by Dr. Mark Majesky, University of North Carolina, Chapel Hill, NC) was suspended in $5 \mathrm{mM} \mathrm{NaPi}$ (pH 5.5), $50 \mathrm{mM}$ $\mathrm{NaCl}$, and 0.5mM DTT. For antibody blocking studies, rat antiintegrin $\alpha 5$ (Pharmingen) or rat anti-integrin $\alpha \mathrm{v}$ (Pharmingen) antibodies were added to the media at a concentration of 20 $\mu \mathrm{g} / \mathrm{mL}$.

\section{Acknowledgments}

We thank Irene Patinyot, CuiPing Dai, and Trevor Crowell for their technical assistance. We also thank Dr. Patrick P.L. Tam for his training in embryo culture techniques. This work was supported by National Institutes of Health R01-HL61408, U.S. Department of Agriculture 6250-51000-033, and AHA-National SDG 99 9930054N grants to K.K.H.

The publication costs of this article were defrayed in part by payment of page charges. This article must therefore be hereby marked "advertisement" in accordance with 18 USC section 1734 solely to indicate this fact.

\section{References}

Akhurst, R.J., Lehnert, S.A., Faissner, A.J., and Duffie, E. 1990. Tgf $\beta$ in murine morphogenetic processes: The early embryo and cardiogenesis. Development 108: 645-656.

Baldwin, H.S. 1996. Early embryonic vascular development. Cardiovasc. Res. 31: E34-E45.

Baron, M.H. 2001. Induction of embryonic hematopoietic and endothelial stem/progenitor cells by hedgehog-mediated signals. Differentiation 68: 175-185.

Bavik, C.O., Peterson, P., and Eriksson, U. 1995. Retinol-binding protein mediates uptake of retinol to cultured human keratinocytes. Exp. Cell. Res. 216: 358-362.

Bavik, C.O., Ward, S.J., and Ong, D.E. 1997. Identification of a mechanism to localize generation of retinoic acid in rat embryos. Mech. Dev. 69: 155-167.

Belaoussoff, M., Farrington, S.M., and Baron, M.H. 1998. Hematopoietic induction and respecification of a-p identity by visceral endoderm signaling in the mouse embryo. Development 125: 5009-5018.

Byrd, N., Becker, S., Maye, P., Narasimhaiah, R., St-Jacques, B., Zhang, X., McMahon, J., McMahon, A., and Grabel, L. 2002. Hedgehog is required for murine yolk sac angiogenesis. Development 129: 361-372.

Carmeliet, P., Ferreira, V., Breier, G., Pollefeyt, S., Kieckens, L., Gertsenstein, M., Fahrig, M., Vandenhoeck, A., Harpal, K., Eberhardt, C., et al. 1996. Abnormal blood vessel development and lethality in embryos lacking a single vegf allele. Nature 380: 435-439.

Chang, H., Huylebroeck, D., Verschueren, K., Guo, Q., Matzuk, M.M., and Zwijsen, A. 1999. Smad5 knockout mice die at mid-gestation due to multiple embryonic and extraembry- onic defects. Development 126: 1631-1642.

Clagett-Dame, M. and DeLuca, H.F. 2002. The role of vitamin a in mammalian reproduction and embryonic development. Ann. Rev. Nutr. 22: 347-381.

Damert, A., Miquerol, L., Gertsenstein, M., Risau, W., and Nagy, A. 2002. Insufficient vegfa activity in yolk sac endoderm compromises haematopoietic and endothelial differentiation. Development 129: 1881-1892.

Dickson, M.C., Martin, J.S., Cousins, F.M., Kulkarni, A.B., Karlsson, S., and Akhurst, R.J. 1995. Defective haematopoiesis and vasculogenesis in transforming growth factor- $\beta 1$ knock out mice. Development 121: 1845-1854.

Downs, K.M. and Davies, T. 1993. Staging of gastrulating mouse embryos by morphological landmarks in the dissecting microscope. Development 118: 1255-1266.

Dyer, M.A., Farrington, S.M., Mohn, D., Munday, J.R., and Baron, M.H. 2001. Indian hedgehog activates hematopoiesis and vasculogenesis and can respecify prospective neuroectodermal cell fate in the mouse embryo. Development 128: $1717-1730$.

Ferrara, N., Carver-Moore, K., Chen, H., Dowd, M., Lu, L., O'Shea, K.S., Powell-Braxton, L., Hillan, K.J., and Moore, M.W. 1996. Heterozygous embryonic lethality induced by targeted inactivation of the vegf gene. Nature 380: 439-442.

Francis, S.E., Goh, K.L., Hodivala-Dilke, K., Bader, B.L., Stark, M., Davidson, D., and Hynes, R.O. 2002. Central roles of $\alpha_{5} \beta_{1}$ integrin and fibronectin in vascular development in mouse embryos and embryoid bodies. Arterioscl. Thromb. Vasc. Biol. 22: 927-933.

Gavrieli, Y., Sherman, Y., and Ben-Sasson, S. 1992. Identification of programmed cell death in situ via specific labeling of nuclear DNA fragmentation. J. Cell. Biol. 119: 493-501.

George, E., Georges-Labouesse, E., Patel-King, R., Rayburn, H., and Hynes, R. 1993. Defects in mesoderm, neural tube and vascular development in mouse embryos lacking fibronectin. Development 119: 1079-1091.

George, E.L., Baldwin, H.S., and Hynes, R.O. 1997. Fibronectins are essential for heart and blood vessel morphogenesis but are dispensable for initial specification of precursor cells. Blood 90: 3073-3081.

Goumans, M.-J., Zwijsen, A., van Rooijen, M.A., Huylebroeck, D., Roelen, B.A.J., and Mummery, C.L. 1999. Transforming growth factor- $\beta$ signalling in extraembryonic mesoderm is required for yolk sac vasculogenesis in mice. Development 126: $3474-3483$

Ignotz, R. and Massague, J. 1986. Transforming growth factor- $\beta$ stimulates the expression of fibronectin and collagen and their incorporation into the extracellular matrix. J. Biol. Chem. 261: 4337-4345.

Ignotz, R., Endo, T., and Massague, J. 1987. Regulation of fibronectin and type i collagen mrna levels by transforming growth factor- $\beta$. J. Biol. Chem. 262: 6443-6446.

Kubota, H., Chiba, H., Takakuwa, Y., Osanai, M., Tobioka, H., Kohama, G.-I., Mori, M., and Sawada, N. 2001. Retinoid x receptor a and retinoic acid receptor $\mathrm{g}$ mediate expression of genes encoding tight-junction proteins and barrier function in $\mathrm{f} 9$ cells during visceral endodermal differentiation. Exp. Cell. Res. 263: 163-172.

Lai, L., Bohnsack, B.L., Niederreither, K., and Hirschi, K.K. 2003. Retinoic acid regulates endothelial cell proliferation during vasculogenesis. Development 130: 6465-6474.

Larsson, J., Goumans, M.-J., Sjostrand, L.J., Rooijen, M.A.v., Ward, D., Leveen, P., Xu, X., Dijke, P.t., Mummery, C.L., and Karlsson, S. 2001. Abnormal angiogenesis but intact hematopoietic potential in tgf- $\beta$ type i receptor-deficient mice. ЕМВО I. 20: 1663-1673. 
Bohnsack et al.

Lee, S.H., Schloss, D.J., and Swain, J.L. 2000. Maintenance of vascular integrity in the embryo requires signaling through the fibroblast growth factor receptor. J. Biol. Chem. 275: 33679-33687.

Morini, M., Piccini, D., De Santanna, A., Levi, G., Barbieri, O., and Astigiano, S. 1999. Localization and expression of integrin subunits in the embryoid bodies of $\mathrm{f} 9$ teratocarcinoma cells. Exp. Cell. Res. 247: 114-122.

Moro, L., Venturino, M., Bozzo, C., Silengo, L., Altruda, F., Beguinot, L., Tarone, G., and Defilippi, P. 1998. Integrins induce activation of egf receptor: Role in map kinase induction and adhesion-dependent cell survival. EMBO J. 17: 66226632.

Niederreither, K., McCaffery, P., Drager, U.C., Chambon, P., and Dolle, P. 1997. Restricted expression and retinoic acidinduced downregulation of the retinaldehyde dehydrogenase type 2 (raldh-2) gene during mouse development. Mech. Dev. 62: $67-78$.

Niederreither, K., Subbarayan, V., Dolle, P., and Chambon, P. 1999. Embryonic retinoic acid synthesis is essential for early mouse post-implantation development. Nat. Genet. 21: 444448.

Noveroske, J.K., Lai, L., Gaussin, V., Northrop, J.L., Nakamura, H., Hirschi, K.K., and Justice, M.J. 2002. Quaking is essential for blood vessel development. Genesis 32: 218-230.

Oh, S.P., Seki, T., Goss, K.A., Imamura, T., Yi, Y., Donahoe, P.K., Li, L., Miyazono, K., ten Dijke, P., Kim, S., et al. 2000. Activin receptor-like kinase 1 modulates transforming growth factor- $\beta 1$ signaling in the regulation of angiogenesis. Proc. Natl. Acad. Sci. 97: 2626-2631.

Ong, D.E., Newcomer, M., and Chytil, F. 1994. Cellular retinoid-binding proteins. In The retinoids (ed. M.B. Sporn, et al.), pp. 283-317. Raven Press, New York.

Sapin, V., Ward, S.J., Bronner, S., Chambon, P., and Dolle, P. 1997. Differential expression of transcripts encoding retinoid binding proteins and retinoic acid receptors during placentation of the mouse. Develop. Dyn. 208: 199-210.

Shalaby, F., Rossant, J., Yamaguchi, T.P., Gertsenstein, M., Wu, X.-F., Breitman, M.L., and Schuh, A.C. 1995. Failure of blood-island formation and vasculogenesis in flk-1 deficient mice. Nature 376: 62-66.

Shanker, G., Olson, D., Bone, R., and Sawhney, R. 1999. Regulation of extracellular matrix proteins by transforming growth factor $\beta 1$ in cultured pulmonary endothelial cells. Cell. Biol. Int. 23: 61-72.

Soldi, R., Mitola, S., Strasly, M., Defilippi, P., Tarone, G., and Bussolino, F. 1999. Role of $\alpha v \beta 3$ integrin in the activation of vascular endothelial growth factor receptor-2. EMBO $\mathrm{T}$. 18: $882-892$.

Soprano, D. and Blaner, W. 1994. Plasma retinol-binding protein. In The retinoids (ed. M.B. Sporn, et al.), pp. 257-281. Raven Press, New York.

Ulven, S.M., Gundersen, T.E., Weedon, M.S., Landaas, V.O., Sakhi, A.K., Fromm, S.H., Geronimo, B.A., Mosakaug, J.O., and Blomhoff, R. 2000. Identification of endogenous retinoids, enzymes, binding proteins, and receptors during early postimplantation development in mouse: Important role of retinal dehydrogenase type 2 in synthesis of all-trans-retinoic acid. Dev. Biol. 220: 379-391.

Yang, J., Rayburn, H., and Hynes, R. 1993. Embryonic mesodermal defects in $\alpha 5$ integrin-deficient mice. Development 119: 1093-1105.

Yang, J.T., Bader, B.L., Kreidberg, J.A., Ullman-Cullere, M., Trevithick, J.E., and Hynes, R.O. 1999. Overlapping and independent functions of fibronectin receptor integrins in early mesodermal development. Dev. Biol. 215: 264-277. 


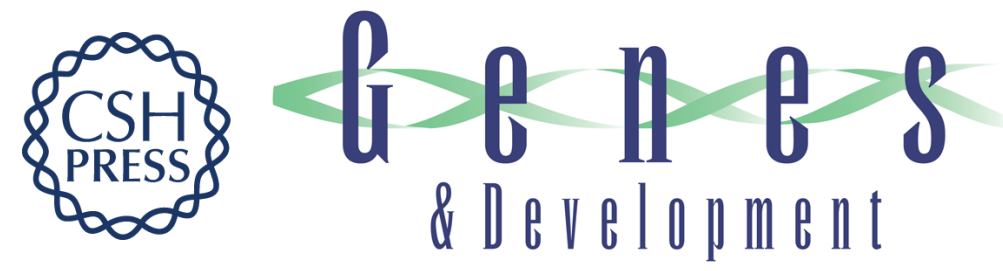

\section{Signaling hierarchy downstream of retinoic acid that independently regulates vascular remodeling and endothelial cell proliferation}

Brenda L. Bohnsack, Lihua Lai, Pascal Dolle, et al.

Genes Dev. 2004, 18:

Access the most recent version at doi:10.1101/gad.1184904

References This article cites 39 articles, 19 of which can be accessed free at: http://genesdev.cshlp.org/content/18/11/1345.full.html\#ref-list-1

License

Email Alerting

Receive free email alerts when new articles cite this article - sign up in the box at the top Service right corner of the article or click here.

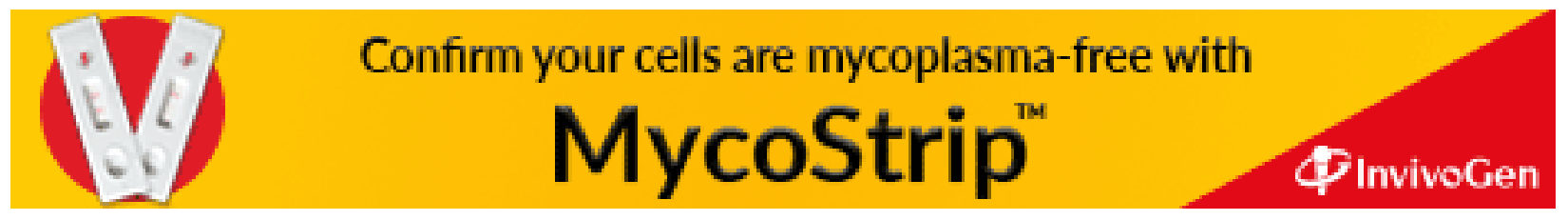

